\title{
AN ECONOMIC STUDY OF CURRENT POSITION OF COTTON CROP IN GHARBIA GOVERNORATE
}

\author{
OMAR AHMAD BADR, WAGIH ABD-EL-AZIZ FARRAG \\ and MOHAMED A. MOBARACK
}

Agricultural Economics Research Institute, ARC, Doki, Giza.

(Manuscript received 30 July 2017)

\begin{abstract}
$\mathrm{T}$ he cotton crop stayed for many decades one of the most important strategic crops in Egypt Ggenerally, and in Gharbia Governorate especially, besides being one of the sources of foreign currency, but it has been noted recently the cultivated areas of cotton is declining by $61 \%$ than it was the season of 1991, the total production has also declined by about $73 \%$ from what it was in the same season, cotton exports declined by about $80 \%$ than the 2001 year at the level of the Republic, as in Gharbia Governorate, the cultivated area of cotton declined by about $94 \%$ from what it was the season of 1991 , the total production has decreased by about $93 \%$ from what it was in the same season. The focus of the research problem in the reluctance of farmers for the cultivation of cotton in Egypt generally, and in Gharbia Governorate especially and decreasing the cultivated area, and decline in the total production OF cotton in Governorate. The study showed the cultivated cotton area in Gharbia is decreasing at an annual rate of about $10 \%$ during the search period, at the level of 0.01 , As the decrease in total production volume at an annual rate of about $9 \%$ during the same period, at the same level and the average productivity per feddan in first category reached about 7.19 kentar and about 7.75 kentar in the second category in sample research. The study showed that the most important factors affecting the production in first category in function are the amount of human labor and quantity of seeds, the Function was significant statistically at 0.01 and agree with the economic logic where the total elasticity in function reached about 0.74 , and the efficiency of production components, human labor, and a quantity of seeds, where the marginal value reached about 102.5 pounds /manday, and 232.5 pounds $/ \mathrm{kg}$ respectively, where the price of these elements reached about 42.19 pounds/man - day , 5.39 pounds $/ \mathrm{kg}$, where the value of the marginal product of them higher than the price of two elements, So, there are an economic efficiency for these elements The second category it proved the existence of a relationship between the amount of cotton production and independent factors are: the quantity of seeds, and the mechanical labor irrigation at the level of 0.01 where the total elasticity reached about 0.60 , Also, It has proved an economic efficiency to these elements of the function. The research showed from the study of a function of the supply
\end{abstract}




\begin{abstract}
response of cultivated area of cotton, there is an opposite relationship between the area and net return of cotton crop in the previous year, whereas the inverse relationship between the area of cotton and net return of clover feddan in the previous year. Also, there is an inverse relationship between the area of cotton and the net return of maize crop in the previous year,

The study showed from the function of supply response of cotton crop, there is necessary response period to the farmer about 2.1 years.
\end{abstract}

\title{
RECOMMENDATIONS
}

It should be determine the farm price for cotton crop before agricultural season encouraging the farmers to cultivate the crop.

It must encourage the contract cultivation for cotton crop which solving the problem of marketing cotton crop.

It must support cotton farmers by saving and reduce the price of production requirements encouraging the farmers to cultivate the cotton crop without the competition crops.

It must determine the farm price of cotton with linking the guarantee price with net return of competition agricultural crops.

The research recommended with cultivating the cotton in large scale farms to reduce the production cost and achieve net high return. 


\title{
دراسة اقتصادية للوضع الراهن لمحصول القطن في محافظة الغربية
}

\author{
عمر أحمد ، وجيه عبد العزيز فراج و محمد عبد الستار مبارك
}

\section{معهز بحوث الاقتصاد الزراعى- مركز البحوث الزراعية- دقى - جيزة (الملخص}

ظل محصول القطن لعقود طويلة أحد أهم المحاصيل الاسترانيجية في مصر وخاصة في محافظة الغربية ، بالاضافه لكونه أحد مصادر النقد الأجنبي ، إلا أنه تلاحظ في الاونة الأخيرة

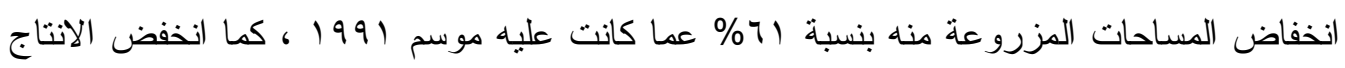

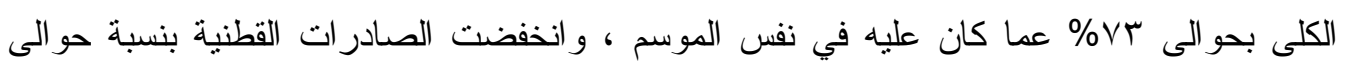
• .

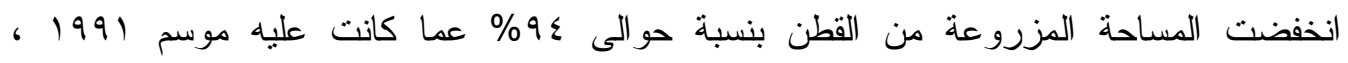
و انخفض الانتاج الكلى بنحو ب9\% عما كان عليه في نفس الموسم .

ونتركز مشكلة البحث في عزوف الزراع عن زراعة محصول القطن فى مصر بصفة عامة وفى محافظة الغربية بصفة خاصة ، مما ادى الى تناقص المساحة المزروعة ، و وانخفاض الانتاج الكلى منه بالمحافظة ،وربما يرجع ذلك لاهمال الحكومة هذا المحصول وعدم الاهنمام بالصناعات القائمة عليه مما يترثب على ذلك فقدان مكانة مصر فى الاسو اق العالمية .

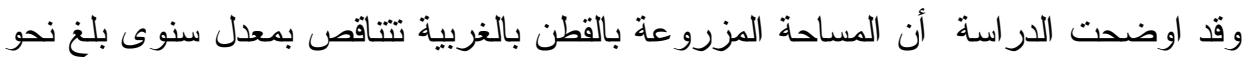

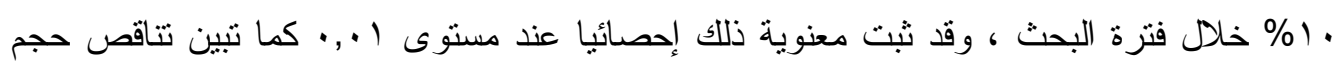

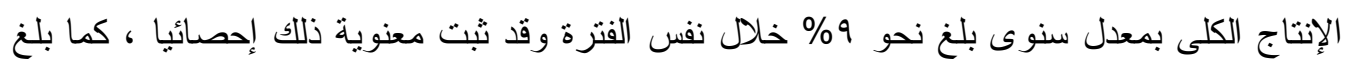

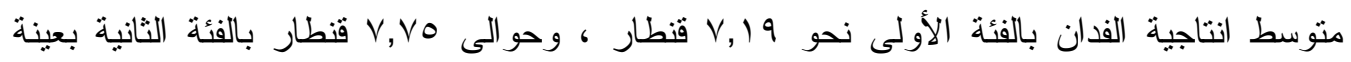
البحث. اثل

كما تبين من الدراسة ان اهم العوامل المؤثزة على الانتاج بالدالة بالفئة الاولى هى مقدار

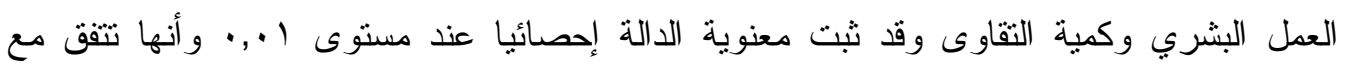
المنطق الاقتصادى حيث بلغت المرونة الاجمالية بالدالة نحو ع V, · ، كما نبين كفاءة عنصري الانتاج

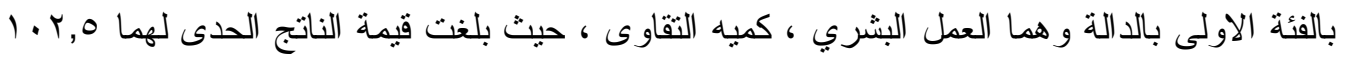

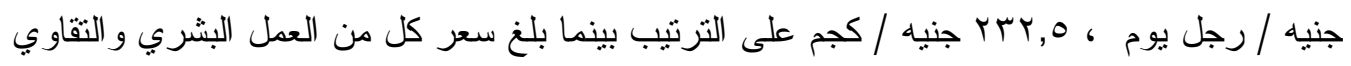

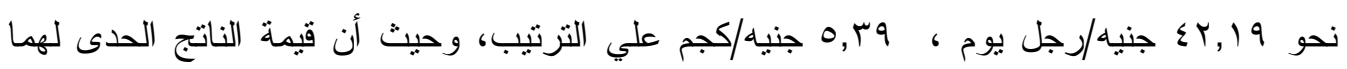

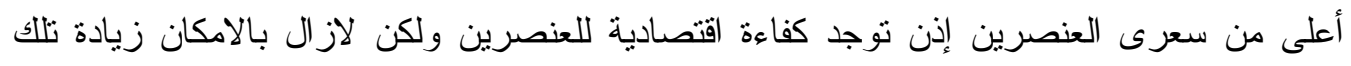
الكفاءة حتي ينساوي قيمة الناتج الحدي للعنصر مع سعره السائد في السوق، اما بالنسبة للفئة الثانية

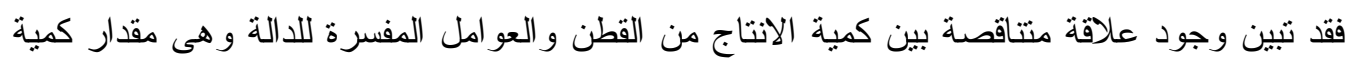

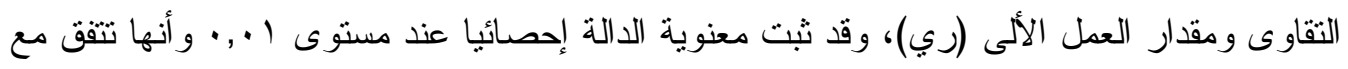

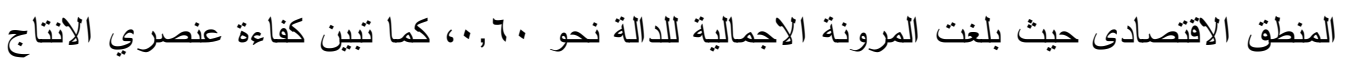




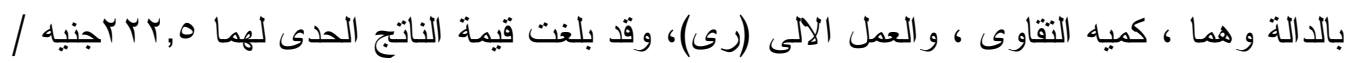

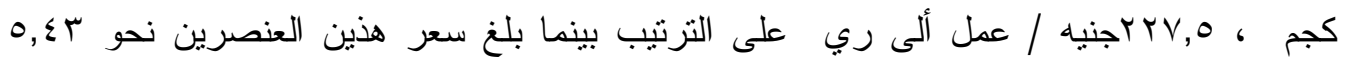

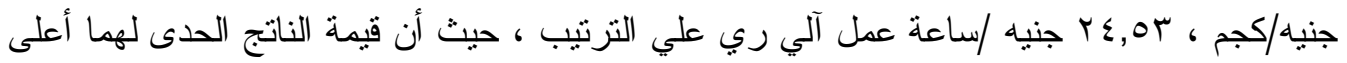
من سعرى العنصرين ، أى نوجد كفاءة اقتصادية للعنصرين وممكن زيادتهما حتى يتساوى قيمة الناتج الحدى مع سعر العنصرين. وبدر اسة أهم مقاييس الكفاءة الاقتصادية لمحصول القطن ، تنين أن عائد الجنيه المستثر بلغ نحو 99, • ، 0 ., 1 جنيه للفئتين الأولى و الثانية على الترتيب ، وبلغ معدل الكفاءة الاقتصادية لانتاج

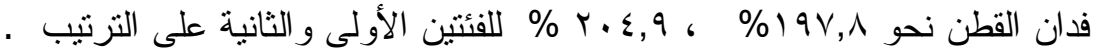

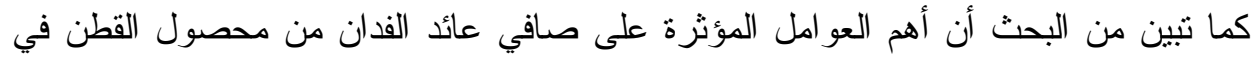
الفئة الأولى و الثانية هى كمية الاتتاج من الفدان ، وقيمة مستلزمات الانتاج ، وإجمالى قيمة العمل وقد

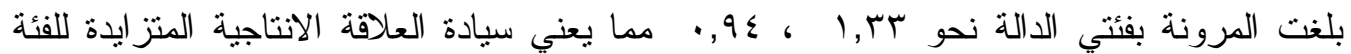
الأولى ، و المتتاقصة للفئة الثانية على الترتيب ، كما أتضح من در اسة دالة استجابة العرض للمساحة

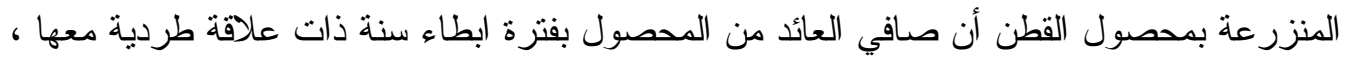
بينما العلاقة عكسية مع صافي العائد الفدانى من محصول البرسيم بفترة ابطاء سنة وهو محصول منافس وهذا يؤثز على قرار المزارعين بالاتجاه نحو زر اعة المحاصيل المنافسة لمحصول القطن ، و أيضا هناك علاقة عكسية مع صافي العائد الفدانى من محصول الذرة الثامية بفترة ابطاء سنة وهو محصول منافس أيضا وذللك بمرونة اجمالية ( -1, 1, ) وتنين من دالة استجابة العرض للمحصول

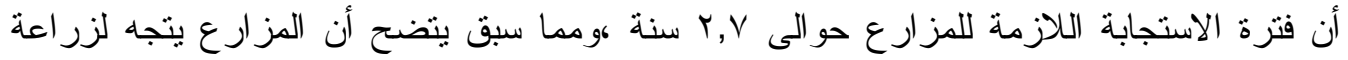

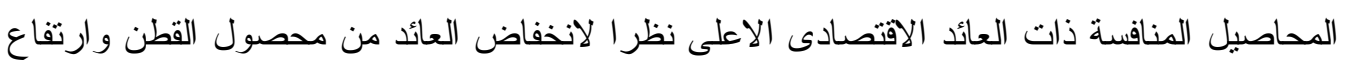

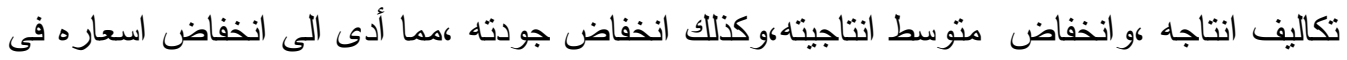

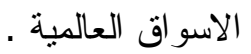

\section{مقدمة}

ظل محصول القطن لعقود طويلة أحد أهم المحاصيل الإستر اتيجية في مصر ومصدر هام من

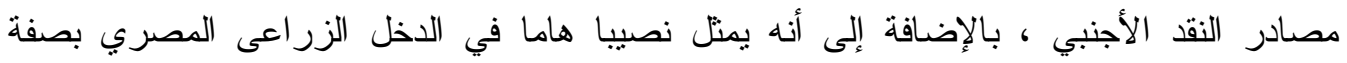
خاصة و الدخل القومى بصفة عامة ، وذللك لما يتصف به القطن المصري بتفوقه على الأقطان العالمية من حيث طول التيلة ونعومتها وجودتها ، إلا أنه فى الاونه الأخيرة تناقصت بهن مساحته

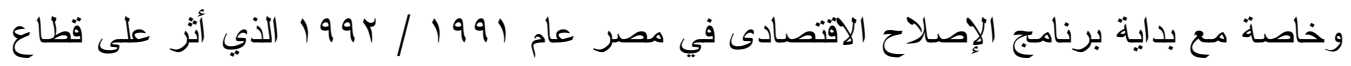
القطن بالتحول إلي سياسة اقتصاديات السوق وتخلت الدولة عن دور هالفرض نركيب محصولي تحدد فيه المساحة المستهدف زر اعتها ، و أيضا تخلت عن دعم مستلزمات الانتاج وتسويق ونسات المحصول

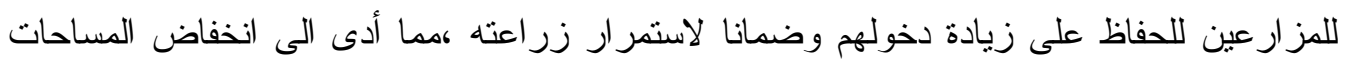
المزروعة منه على مستوى الجمهورية من

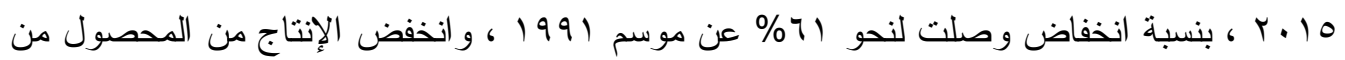

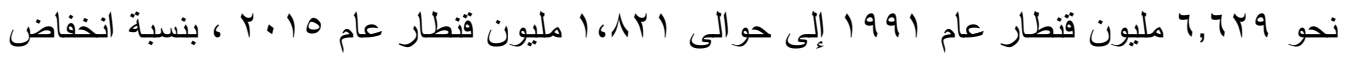




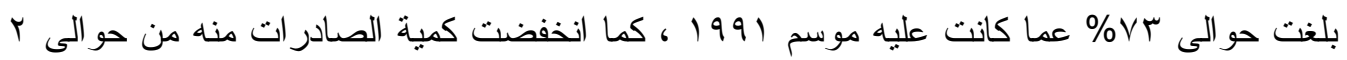

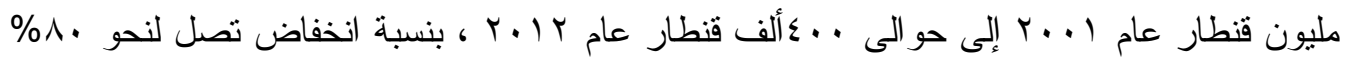

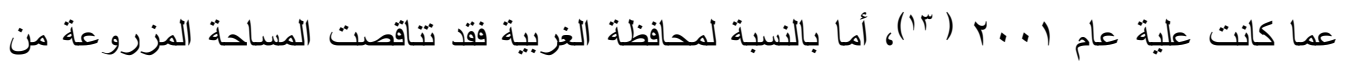

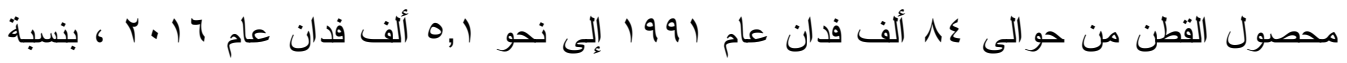
انخفاض وصلت لنحو ؟9\% عما كانت عليه موسم 1991 ، كما تتاقصت كمية الإنتاج من

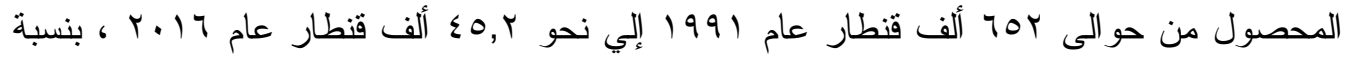

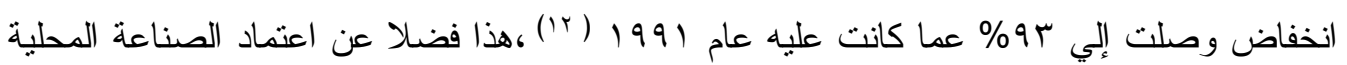

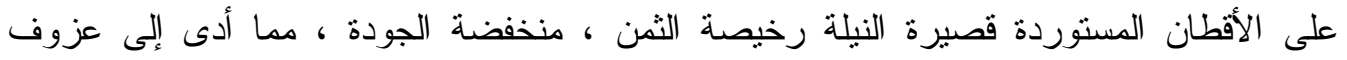

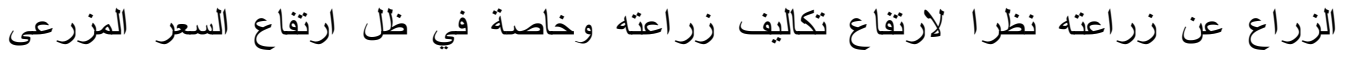

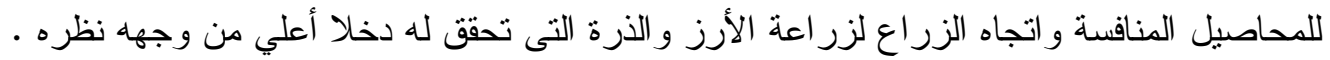

\section{مشكلة البحث}

تكمن مشكلة البحث فى انخفاض المساحة المزروعة بالقطن ،وربما يرجع ذلك الى أن الدولة

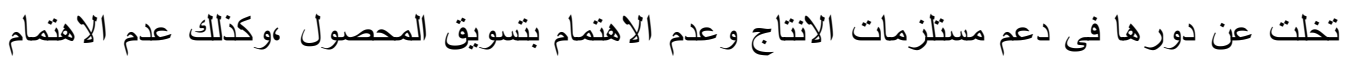
بصناعة المنسوجات و استيراد الاقطان القصيرة و المتوسطة التبلة ،مما ترتب عليه انخفاض المساحات المزروعة منه وبالتالى انخفاض الانتاج الكلى ،وفقدان مصر لمكانتها فى الاسواق العالمية

\section{الههف من البحث}

در اسة الوضع الر اهن لمحصول القطن على مستوى محافظة الغربية وذللك من خلال :

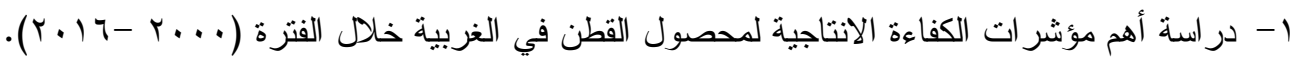
r- ثقدير دالة الانتاج الفيزيقية بعينة البحث بمحافظة الغربية.

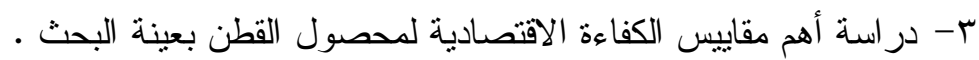
ع - در اسة أهم العو امل المؤثرة على صافي عائد انتاج القطن بعينة البحث في محافظة الغربية .

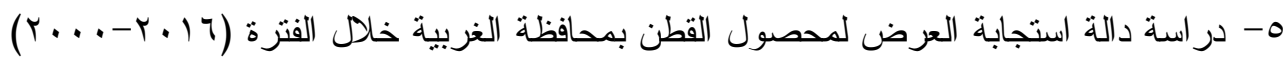
الأسلوب البحثي ومصادر البيانات

يعتمد البحث على الأسلوب الوصفي والكمى للبيانات المستخدمة ، حيث تم استخدام معدلات الاتجاه الزمنى العام ، ومعادلات الانحدار الخطى المتعدد ، وبعض مؤشرات التهل الكفاءة الانتاجية

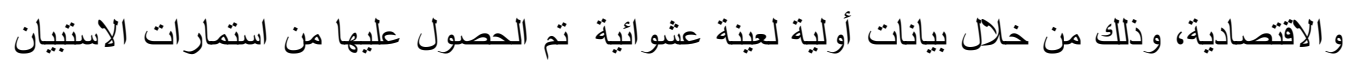
لمزارعى القطن بمر اكز محافظة الغربية ، بالإضافة إلي بيانات مديرية الزراعة بالغربية ،ادارة

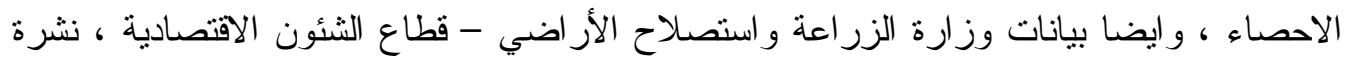

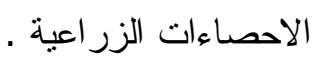




\section{اختيار عينة البحث}

نم اختبار مركزى المحلة الكبرى وقطور بمحافظة الغربية وفقاً لأهميتها النسبية حيث يمثلان

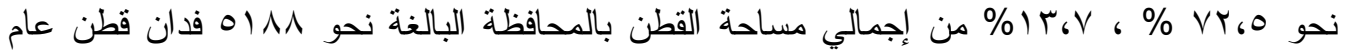
17 قريتى : سامول ، و المعتمدية بمركز المحلة الكبرى ، وقريتى سماتاى ، وعزبة ماهر فى مركز

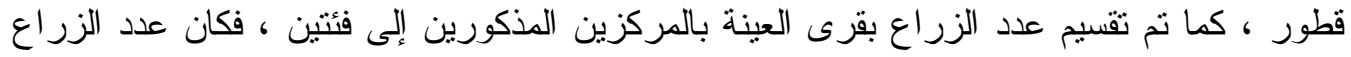

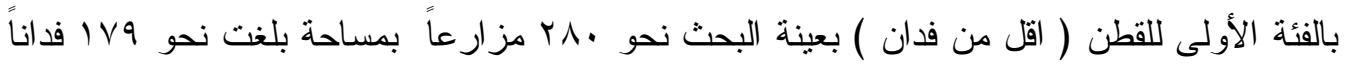

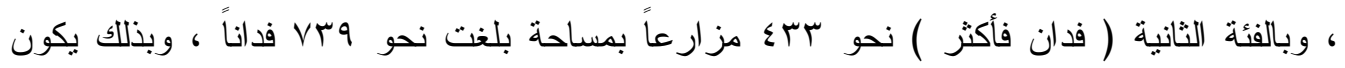

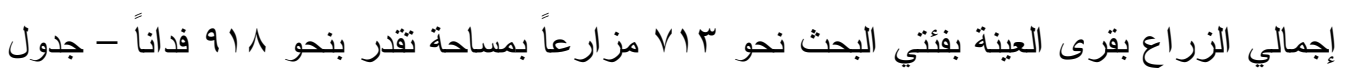

وتم تحديد حجم العينة بنحو ربا مشاهدة(') ، فكان عدد المشاهدات المختارة بالفئة الأولى

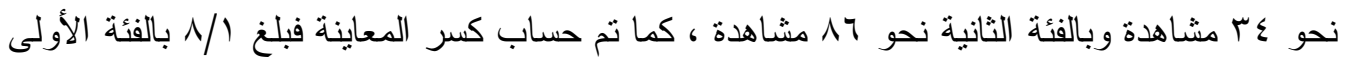

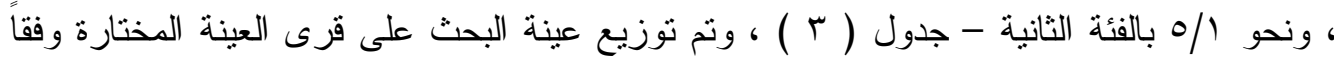
لكسر المعاينة فكان نصيب قريتى سامول و المعتمدية بمركز المحلة الكبرى نحو 0 ، V مشاهدة بالفئة

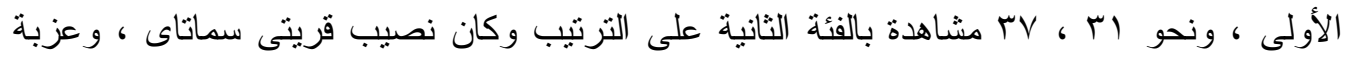

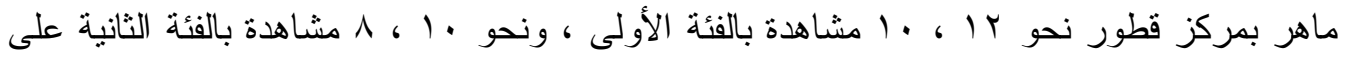
الترتيب وبذللك يكون إجمالي المشاهدات بالفئة الأولى بقرى العينة نحو عب مشاهدة ، وبالفئة الثانية نحو بم مشاهدة ، وبذلك يكون إجمالى العينة لمزارعى القطن بالقرى المذكورة فى مركزى البحث

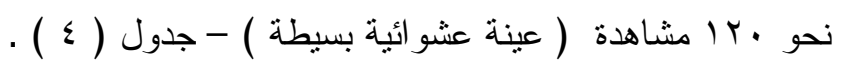

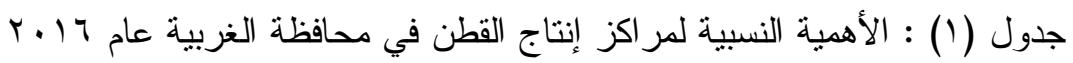

\begin{tabular}{|c|c|c|c|c|c|}
\hline$\%$ & عدد الزراع & $\%$ & ( بالفدان) & المركز & r \\
\hline$\neg, V$ & צ & $7, r$ & rrV & طنطا & 1 \\
\hline$v 1,0$ & 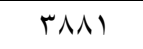 & $V Y, O$ & rVTr & المحلة الكبري & r \\
\hline$I T, V$ & $V \varepsilon \varepsilon$ & IT,V & VIT & قطور & r \\
\hline $1, \varepsilon$ & $V Y$ & I,r & $7 V$ & زفتي & $\varepsilon$ \\
\hline$\cdot r$ & 17 & $\cdot, r$ & $1 \leqslant$ & السنطة & 0 \\
\hline$\cdot, 1$ & 7 & $\cdot, 1$ & 0 & كفر الزيات & 7 \\
\hline $7, r$ & q & 0,1 & $r \cdot 1$ & بسيون & V \\
\hline---- & ---- & ---- & --- & سمنود & $\wedge$ \\
\hline $1 \ldots$ & $0 \leqslant Y T$ & $1 \ldots$ & 0111 & لإجمالي & \\
\hline
\end{tabular}

المصدر : جمعت وحسبت من مديرية الزر اعة بالغربية ، سجلات إدارة المكافحة الحقلية ، بيانات غير منشورة .

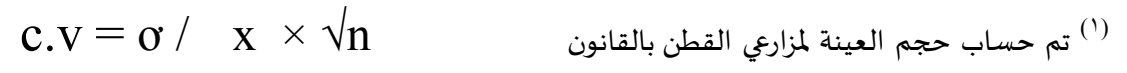


جدول (r) : إجمالي المساحة المزروعة بالقطن بالقرى المختارة بمركزي العينة

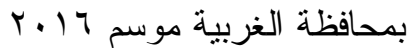

\begin{tabular}{|c|c|c|c|c|c|c|c|c|}
\hline \multicolumn{2}{|c|}{ الفئة الثانية } & \multicolumn{2}{|c|}{ الفئة الأولي } & \multirow{2}{*}{ المزاحة } & \multirow{2}{*}{ المز ارعين } & \multirow{2}{*}{ القختارة } & \multirow[b]{2}{*}{ المركز } & \multirow[b]{2}{*}{ 5 } \\
\hline المساحة & الحائزين & المساحة & عدد الحائزين & & & & & \\
\hline$r \cdot q$ & 107 & r^ & rv & (rv & 194 & سامول & \multirow{2}{*}{ الكبرية } & 1 \\
\hline rVA & 110 & 0. & $0 \wedge$ & rra & $r \leq r$ & المعتمدية & & r \\
\hline ONV & $r \leqslant 1$ & VA & 90 & 770 & \& & \multicolumn{3}{|c|}{ الجملــــــــــــة } \\
\hline 94 & 0. & 0 . & $1 \ldots$ & $1 \leq r$ & 10. & سماتاي & \multirow{2}{*}{ قطور } & 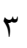 \\
\hline 7. & $\varepsilon r$ & 01 & 10 & 111 & IrV & عزبة ماهر & & $\varepsilon$ \\
\hline lor & 94 & $1 \cdot 1$ & 110 & ror & TVV & \multicolumn{3}{|c|}{ الجملـ الجـ } \\
\hline$v r q$ & سזו & 189 & rA. & 911 & VIT & \multicolumn{3}{|c|}{ إجمالي } \\
\hline
\end{tabular}

الصددر : جمعت وحسبت من مديرية الزراعة بالغربية ، سجلات إدارة الإحصاء ، بيانات غير منشورة .

جدول (r) : نوزيع عينة البحث المختارة من الحائزين لمساحات القطن علي فئات العينة

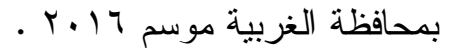

\begin{tabular}{|c|c|c|c|c|c|c|c|c|c|c|}
\hline كسر & $\begin{array}{c}\text { الحائزين } \\
\text { المختارين } \\
\text { اللفئة }\end{array}$ & الوالمط المنسي & الهنسي & نسبة الحئزين فيد & المساحة & الحبية عدد & بالفدان & الحائزين & الفئات & 5 \\
\hline $\begin{array}{l}\frac{1}{1} \\
\wedge\end{array}$ & $\Gamma \varepsilon$ & rA, ro & $Y V, T V$ & $V Y 0, V V$ & 19.0. & $r q, r v$ & 1199 & rA. & الأولي : أقل & 1 \\
\hline $\begin{array}{l}1 \\
0\end{array}$ & $\Lambda t$ & $v 1,70$ & 79,94 & $\{\Lambda \Lambda \Lambda, \vee V$ & $\lambda_{\cdot}, 0$. & $Y^{\prime}, V \mu$ & vrq & Tr & فانان فأثنا : & r \\
\hline - & $1 r$. & $1 \ldots$ & $9 Y, 09$ & ----- & $1 \ldots$ & $1 \ldots$ & 911 & VIr & الإجمالي & \\
\hline
\end{tabular}

المصدر : جمعت وحسبت من:

1- مديرية الزر اعة بالغربية ، سجلات إدارة الإحصاء ، بيانات غير منشورة .

ب- الإدارة الزر اعية بمركزى المحلة الكبري وقطور ، سجلات إدارة الإحصاء ، بيانات غير منشورة . 
جدول (ع) : توزيع عينة البحث علي قري العينة المختارة وفقا لحجم الفئة بمزارع القطن

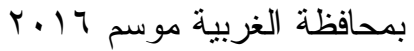

\begin{tabular}{|c|c|c|c|c|c|c|c|c|c|c|c|c|}
\hline \multicolumn{5}{|c|}{ الفئة الثانية (فنان فأكثر) } & \multicolumn{5}{|c|}{ الفئة الأولي (أقل من فـان) } & \multirow[b]{2}{*}{ القرية } & \multirow[b]{2}{*}{ المركز } & \\
\hline الدختائزين & $\%$ & بالفدانة & $\%$ & الحائزين & الحائز عدن & $\%$ & المساحة & $\%$ & لحائزي & & & \\
\hline$\mu$ & 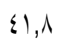 & $r .9$ & r.,. & 107 & 。 & 10,1 & YA & $\mid r, r$ & rv & سامول & \multirow{2}{*}{ الكبري } & \multirow{2}{*}{1} \\
\hline rv & $r v, T$ & YYA & $\{r, Y$ & 110 & v & $r v, q$ & 0. & $r_{\cdot, Y}$ & 01 & الدتمدية & & \\
\hline 1. & 15,0 & $9 \mathrm{r}$ & 11,0 & 0. & ir & $r v, q$ & 0. & $r 0, Y$ & $1 .$. & سماناي & \multirow[b]{2}{*}{ قطور } & \multirow[b]{2}{*}{ r } \\
\hline$\wedge$ & $\lambda, 1$ & $\gamma$ & $q, Y$ & $\{r$ & 1. & r, Yo & 01 & $r_{\bullet, \xi}$ & 10 & عزه مزبة & & \\
\hline$\Lambda 4$ & 1.. & $v \Psi q$ & 1.. & Tr & r؛ & 1.. & 189 & 1.. & rA. & \multicolumn{3}{|c|}{ الإجمالي } \\
\hline
\end{tabular}

$$
\text { المصدر : جمعت وحسبت من : }
$$

1- مديرية الزراعة ، سجلات إدارة الإحصاء ، بيانات غير منشورة. r- الإدارة الزر اعية بمركزى المحلة الكبري وقطور ، سجلات إدارة الإحصاء ، بيانات غير منشورة .

\section{النتائج البحثية}

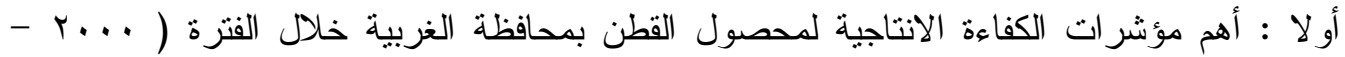

1- تطور المساحة المزروعة بمحصول القطن

بدر اسة البيانات الواردة بجدول (1) بالملحق تبين أن المساحة المزروعة بمحصول القطن

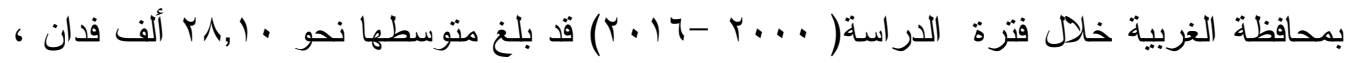

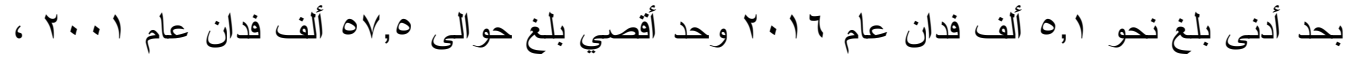

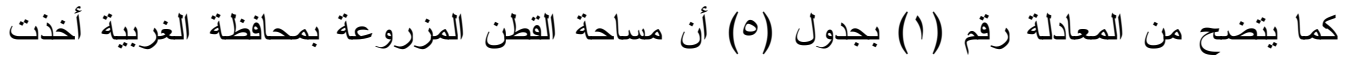

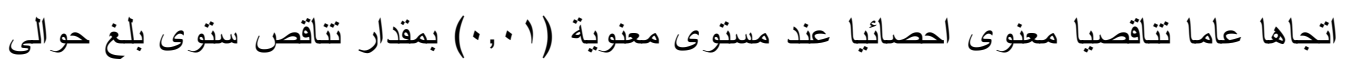

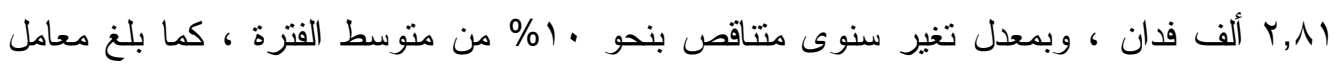

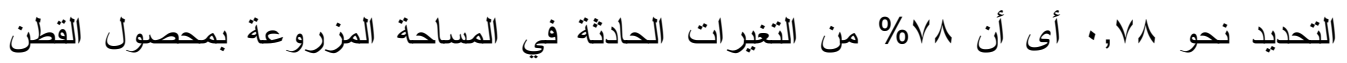

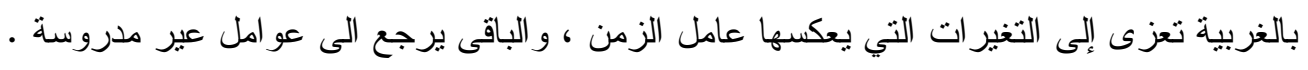
r

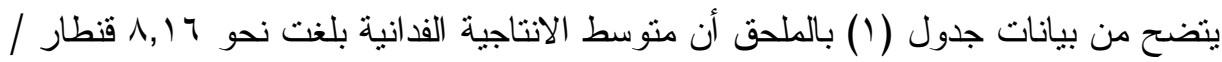

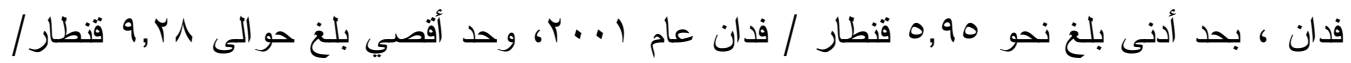

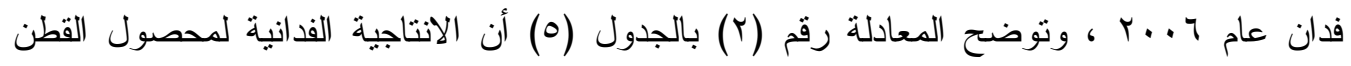
بمحافظة الغربية أخذت اتجاها عاما تز ايديا معنوى احصائيا عند مسنوى معنوية (0. . •) ، بمقدار 
زيادة بلغ نحو V乏, • قنطار / فدان وبمعدل تغير سنوى بلغ نحو 0,V7\% من منوسط الفترة ، وقد

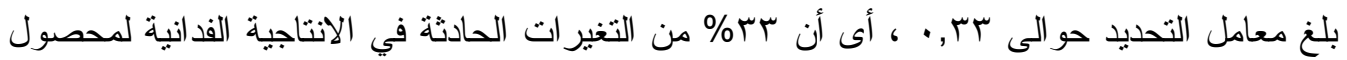
القطن تعزى إلي التغير ات التي يعكسها عامل الزمن ، و الباقى يرجع الى عو امل غير مدروسة .

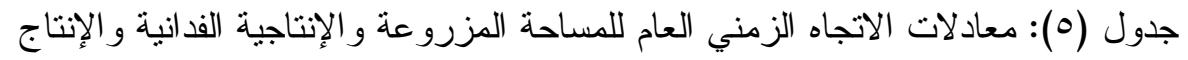

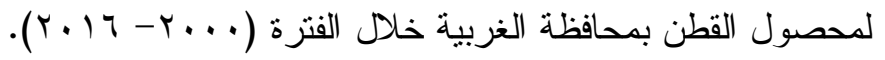

\begin{tabular}{|c|c|c|c|c|c|c|}
\hline $\mathrm{F}$ & $\begin{array}{l}- \\
R^{2}\end{array}$ & م السنوي & منو سط الفترة & المعادلة المقدرة & البيان & e \\
\hline $52.68 * *$ & 0.78 & -10.0 & 28.1 & $\begin{array}{r}\hat{Y}_{1 i}=53.35-2.81 L X_{i} \\
(-7.26)^{* *}\end{array}$ & المسألادة المزروعة & 1 \\
\hline $6.32^{*}$ & 0.33 & 5.76 & 8.16 & $\begin{array}{r}\hat{Y}_{2 i}=7.73+0.47 L X_{i} \\
(2.51)^{* *}\end{array}$ & قالإر فنتاجية & r \\
\hline $48.41 * *$ & 0.76 & -9.0 & 224.1 & $\begin{array}{r}\hat{Y}_{3 i}=405.57-20.17 L X_{4} \\
(-6.96)^{* *}\end{array}$ & الألأنتاج الكلي & $r$ \\
\hline
\end{tabular}

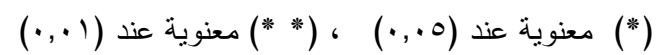

حيث أن

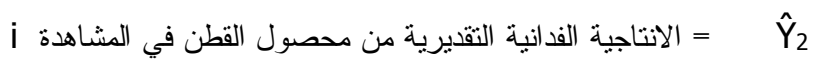

i الانتاج الكلى التقديري من محصول القطن في المشاهدة

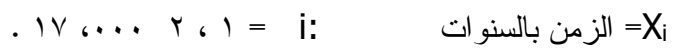

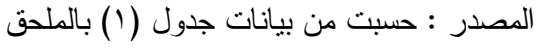

r- الانتاجية الفدانية لمحصول القطن :

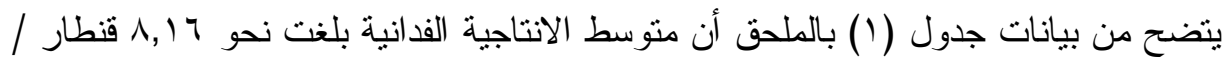

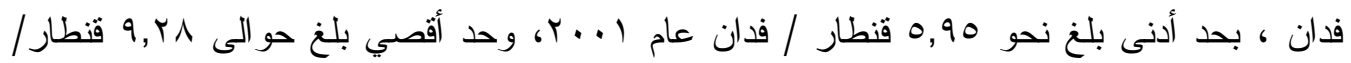

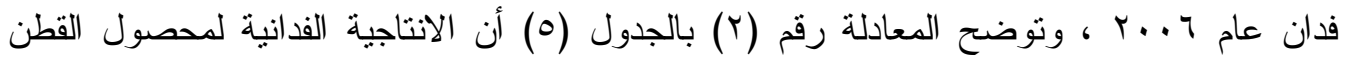
بمحافظة الغربية أخذت اتجاها عاما تز ايديا معنوى احصائيا عند مستوى معنوية (0., •) ، بمقدار

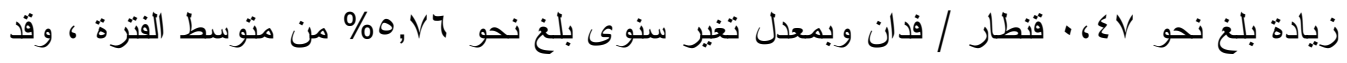

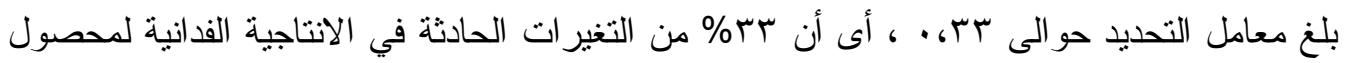

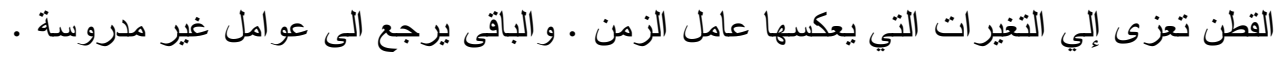
ع - الإنتاج الكلى من محصول القطن :

توضح بيانات جدول (1) بالملحق أن منتسط كمية الانتاج الكلى من محصول القطن

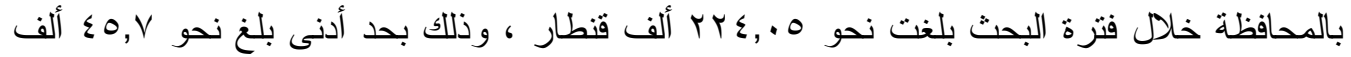

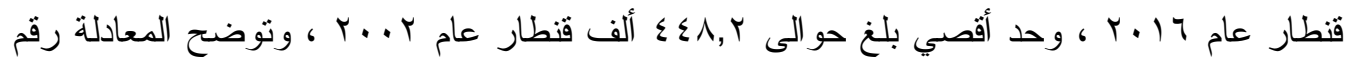

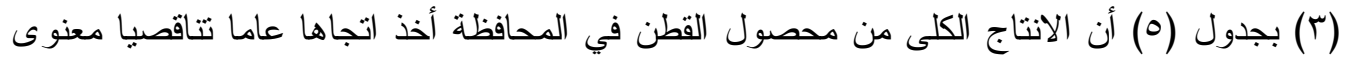


احصائيا عند مستوى (1 +, •) ، بمقدار تتاقص سنوى بلغ نحو Y V Y, ألف قنطار ، وبمعدل تغير

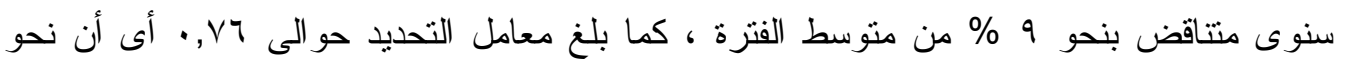
\% من التغيرات الحادثة في الانتاج الكلى لمحصول القطن بالغربية تعزى إلي التغيرات التي

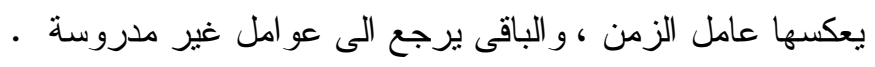

و بدراسة الكفاءة الانتاجية لفدان القطن بفئتى العينة يتضح من جدول (7) ان انتاجية فدان

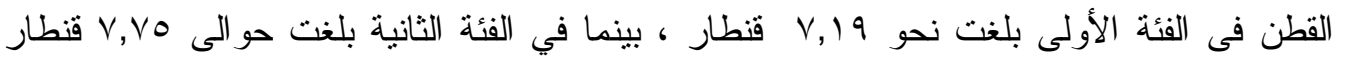

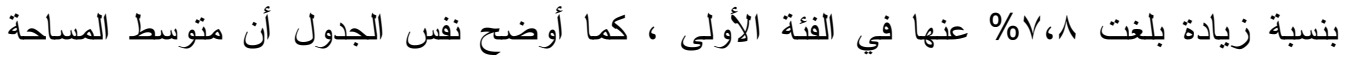

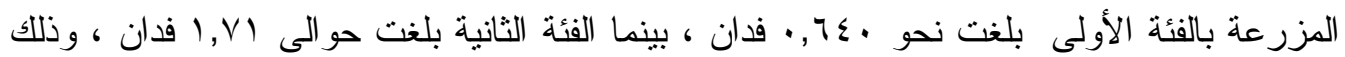

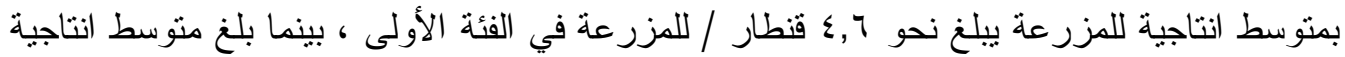

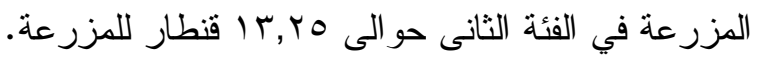

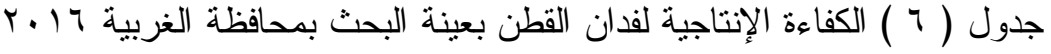

\begin{tabular}{|c|c|c|c|c|c|c|c|}
\hline متوسط إنتاجية & مساحة الفئة & إجمالي الإنتاج & المز ارع & متو سط مساحة & متوسط إنتاجية & الصنف & الفئة الحيازية \\
\hline$v, 19$ & $r, Y Y$ & 107,8 & $r \varepsilon$ & 约 & $\varepsilon, 7$ & جيزة 17 & قالأولى (أقل من \\
\hline$v, v_{0}$ & $1 \leqslant V, \cdot 7$ & $11 \% 9,0$ & $\Lambda 4$ & $1, V_{1}$ & $15, r_{0}$ & جيزة 17 & الثانية (فدان فأكثر ) \\
\hline
\end{tabular}

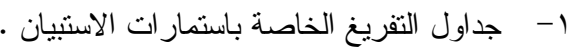

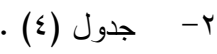

ثانيا: دو ال إنتاج محصول القطن بمحافظة الغربية بعينة البحث :

تعبر دالة الإنتاج عن العلاقة الفيزيقية بين كمية الإنتاج من محصول القطن بالقنطار (

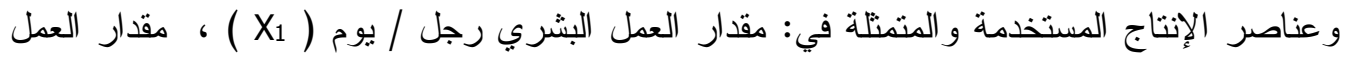

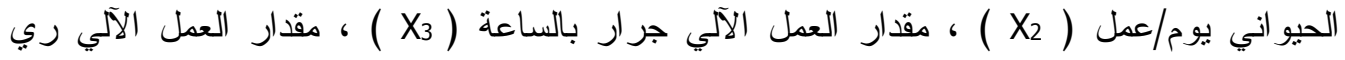

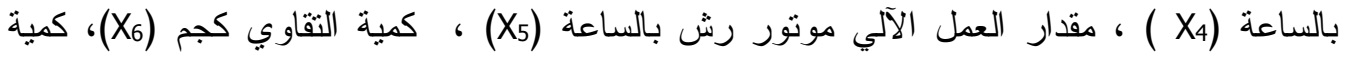

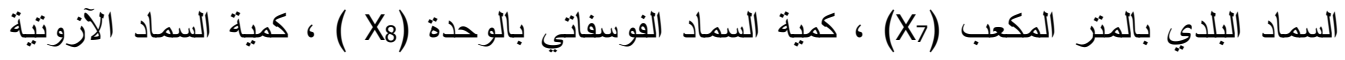

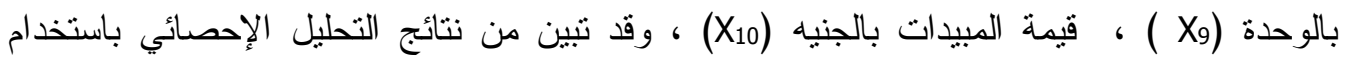
نموذج الانحدار المتعدد الخطي أن أدق النماذج هى الصورة اللوغاريتمية المزدوجة وذللك بإستخدام أسلوب back word

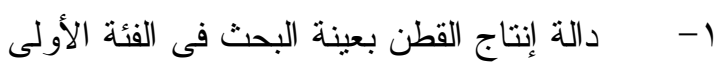

توضح دالة إنتاج القطن رقم ( 1 ) ) بالجدول ( V ) ) أن هنالك علاقة دالية طردية لو غارينهية

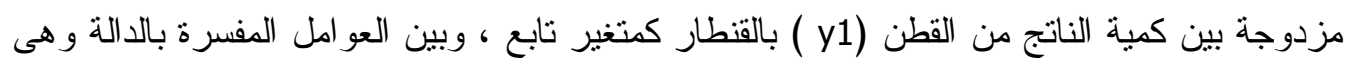

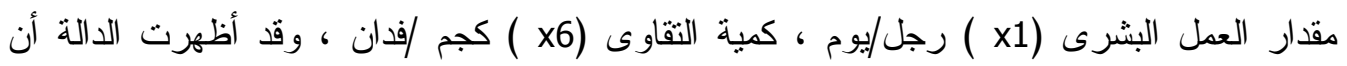

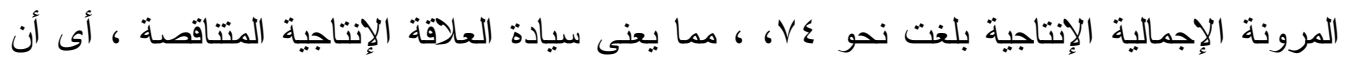


الناتج يزيد بنسبة أقل من زيادة المو ارد الإجمالية بالدالة ، وهذا يشير إلى أن زيادة المو ارد الإجمالية

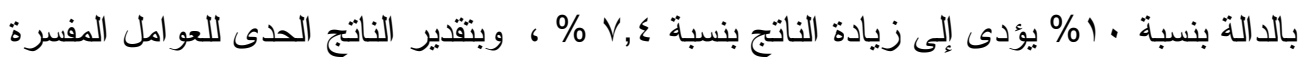

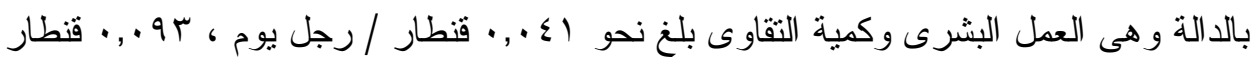

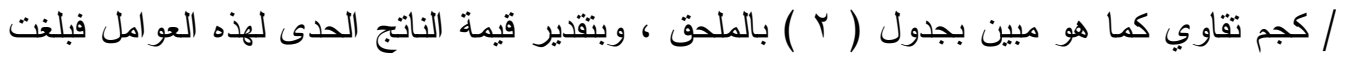

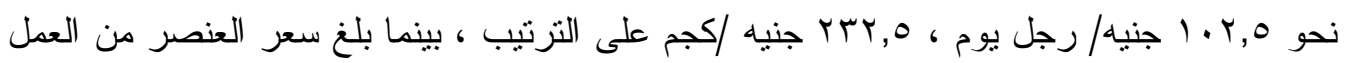

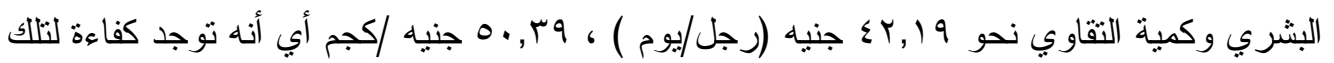

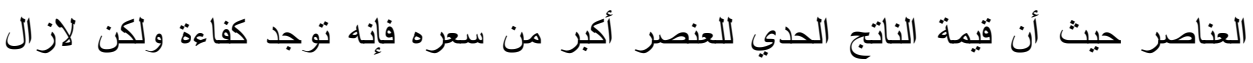

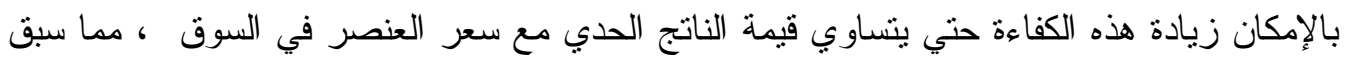

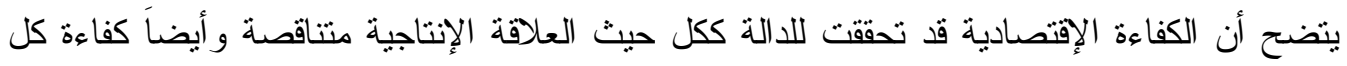

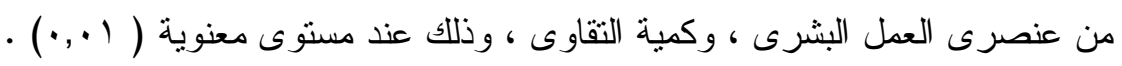

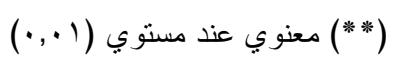

جدول رقم (V) الثقدير الاحصائي لدو ال انتاج محصول القطن بمحافظة الغربية موسم 17 • r.

\begin{tabular}{|c|c|c|c|c|}
\hline $\begin{array}{l}\text { F } \\
\text { المحسوبة }\end{array}$ & $\overline{\mathrm{R}^{2}}$ & المرونة & المعادلة المقدرة & الفئة الحيازية \\
\hline $26.92 * *$ & 0.61 & 0.741 & 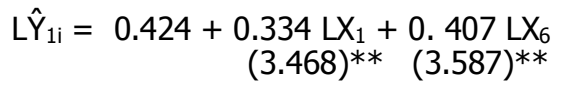 & الفئة الأولي \\
\hline $101.22^{* *}$ & 0.70 & 0.604 & $\begin{array}{rr}L_{2 i}=0.036+0.389 \mathrm{LX}_{6}+ & 0.215 \mathrm{LX}_{4} \\
(7.400)^{* *} & (4.680)^{* *}\end{array}$ & الفئة الثانية \\
\hline
\end{tabular}

حيث أن

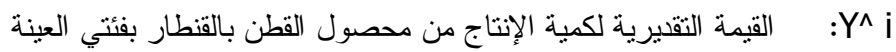

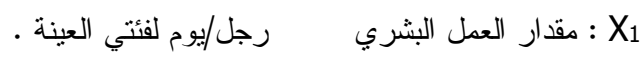

X : X4

X6 : كمية النقاوي = Log : L

المصدر : جمعت وحسبت من استمار ات الإنتيان الخاصة بالبحث

r-دالة إنتاج القطن بعينة البحث فى الفئة الثانية .

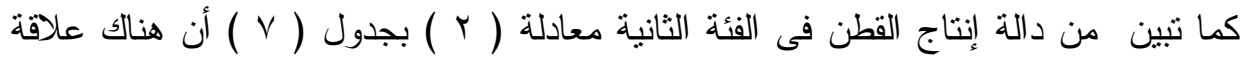

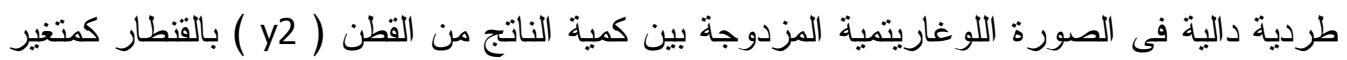

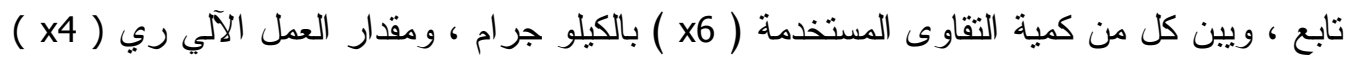

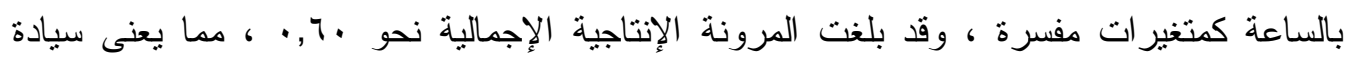

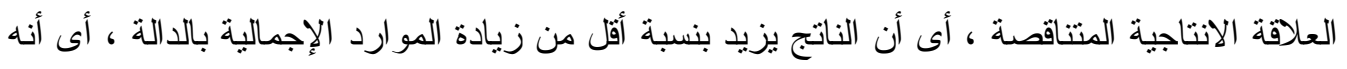

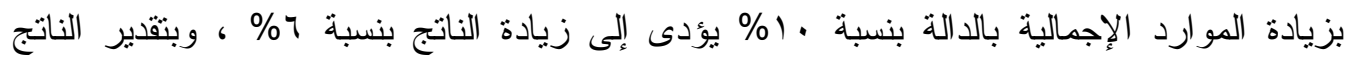

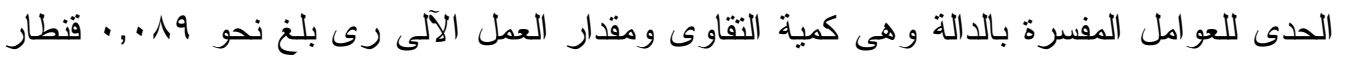

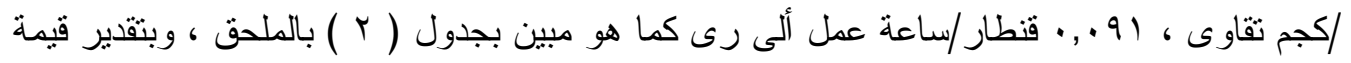




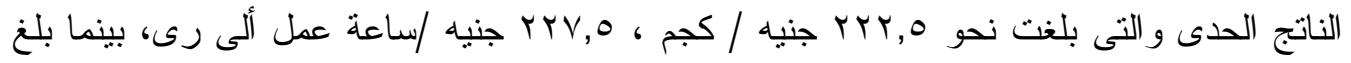

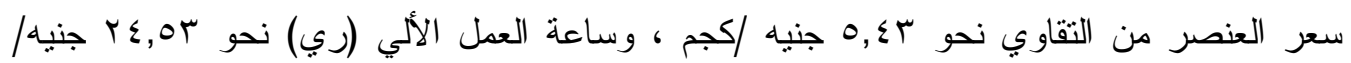
ساعة وحيث أن قيمة الناتج الحدي للعنصر أكبر من سعره ، إذن توجد كفاءة لتلك العناصر ولكن

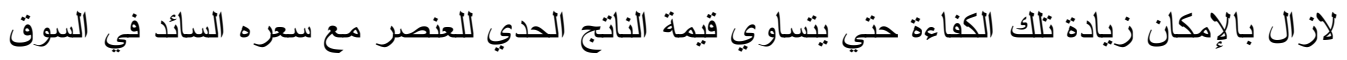

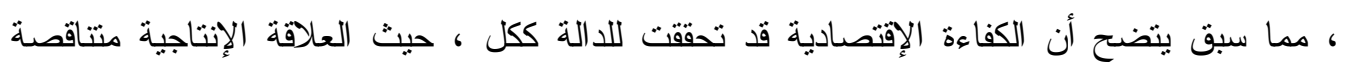

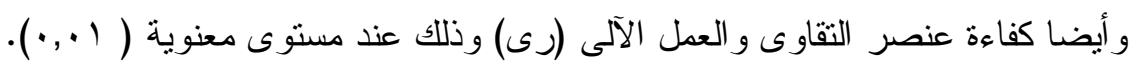
ثالثا : أهم مقاييس الكفاءة الإنتاجية والاقتصادية لمحصول القطن والفيل ولفئنى العينة :

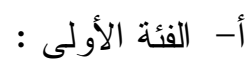

بدر اسة أهم مقاييس الكفاءة الاقتصادية لمحصول القطن ، تبين من جدول رقم (^) أن تكلفة

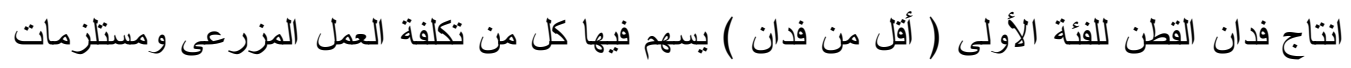
الانتاج بنحو V., المتغيرة البالغة نحو

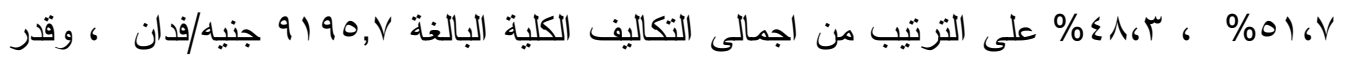

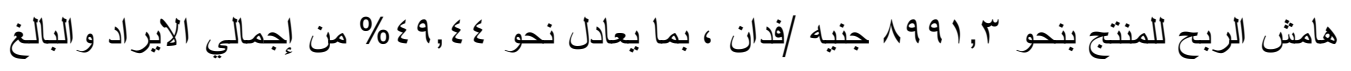

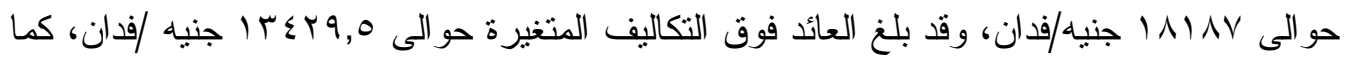
بلغ عائد الجنيه المستثر نحو هو , · جنيه، في حين بلغت الكفاءة الاقتصادية لانتاج الفدان في هذه

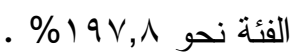

جدول (^) أهم مقاييس الكفاءة الاتتاجية والاقتصادية للفدان من محصول القطن بعينة البحث

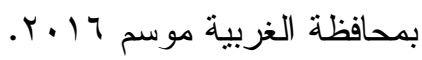

\begin{tabular}{|c|c|c|c|}
\hline 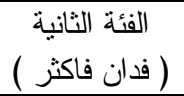 & ( أقل من فدان ) الأولى & ال المتغير ات & 5 \\
\hline rqrs & rory & تكلفة العمل البشرى & 1 \\
\hline$r \cdot, 9$ & $r, 0$ & تكلفة العمل الحيو اني & r \\
\hline$\Lambda r \cdot, \nu$ & AIr,r & تكلفة العمل الالي & r \\
\hline$r \vee \wedge 0, T$ & Trot,V & إجمالى تكلفة العمل المزرعى & $\varepsilon$ \\
\hline $1+4 \cdot, r$ & $1 \leq \cdot r, \Lambda$ & إجمالى تكلفة مستلزمات الاتتاج & $\circ$ \\
\hline $01 \leqslant 0,1$ & $\sum V \odot V, 0$ & التكاليف المتغيرة & 7 \\
\hline$\varepsilon \varepsilon \cdot \wedge, 1$ & $\leqslant \varepsilon r \Lambda, r$ & التكاليف الثابتة & v \\
\hline 9004,9 & $9190, V$ & | التكاليف الكلية & $\Lambda$ \\
\hline $\mathrm{V}, \mathrm{VO}_{\mathrm{O}}$ & $V, 19$ & كمية الانتاج بالقنطار & 9 \\
\hline $190 \times 9$ & $1 \mathrm{NINV}$ & اجمالي الاير اد & 1. \\
\hline \multicolumn{4}{|c|}{ أهم المقاييس الإقتصادية } \\
\hline $1 \ldots Y 0,1$ & $1991, r$ & صافى العائد ( هامش الربح للمنتج ) & 1 \\
\hline $1 \leq \leqslant r r, 1$ & $1 r \leqslant r 9,0$ & العائد فوق التكاليف المتغيرة & $r$ \\
\hline$r, \cdot \leqslant 9$ & $1,9 \vee \wedge$ & إجمالى العائد لإجمالى التكاليف & $r$ \\
\hline $1, \cdot \leqslant 9$ & $\cdot, 9 \vee \wedge$ & عائد الجنيه المستثر & $\varepsilon$ \\
\hline $01, Y$ & $\leq 9, \leqslant \varepsilon$ & نسبة هامش الربح للمنتج \% & 0 \\
\hline$r \cdot \varepsilon, q$ & $19 \vee, \Lambda$ & الكفاءة الإقتصادية \% & 7 \\
\hline
\end{tabular}


توضح مقاييس الكفاءة الاقتصادية لمحصول القطن بهذه الفئة كما هو مبين بجدول (^) أن تكلفة انتاج فدان القطن بهذه الفئة يسهم فيها كل من العمل المزرعى ومستلزمات الانتاج بنحو

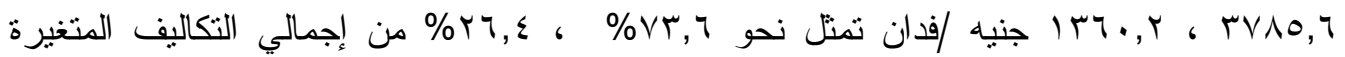
البالغة نحو 0,1 \ـ0 جنيه/فدان علي الترتيب ، بينما تسهم كل من التكاليف المتغيرة و الثابتة بنحو

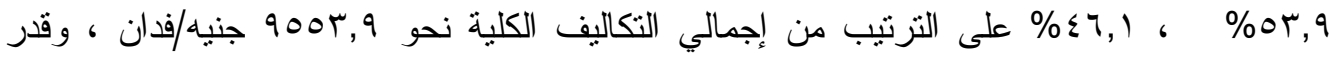

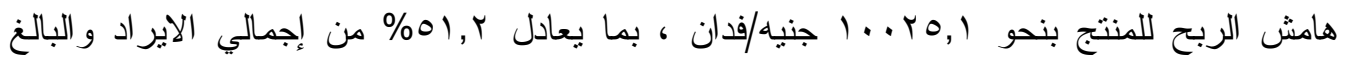

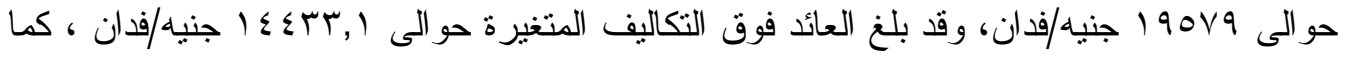

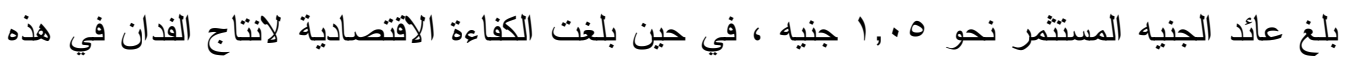
الفئة نحو 9,؟ •r\% ، ، وخلاصة ذلك أن كل من عائد الجنيه المستثمر و الكفاءة الاقتصادية في الفئة

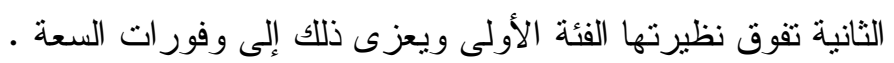
رابعا : أهم العو امل المؤثزة على صافي العائد من انتاج محصول القطن لعينة البحث موسم 17 ــ

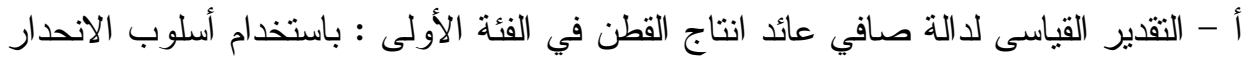
الخطي المتعدد بطريق back word يتضح من المعادلة (1) بالجدول (9) أن هناك علاقة دالية

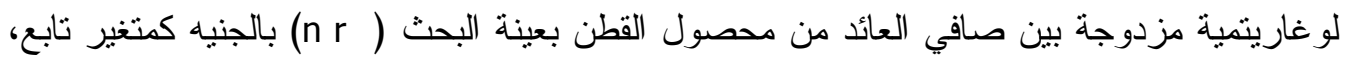

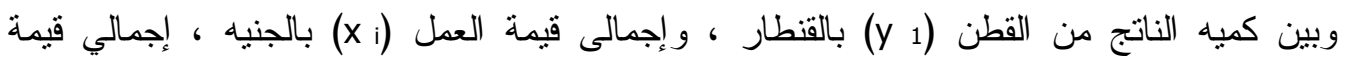

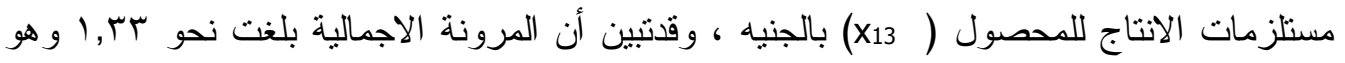

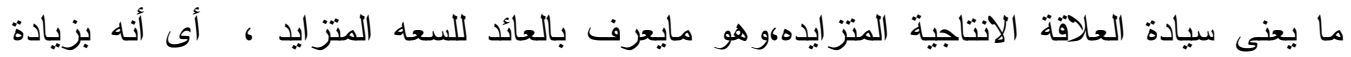
المو ارد الاجمالية بالدالة بنسبة • 1\% تؤدى إلى زيادة صافي العائد من محصول القطن بهذه الفئة

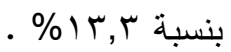

جدول (9) النقاير القياسى لأهم العو امل المؤثرة على صافى العائد من انتاج محصول القطن

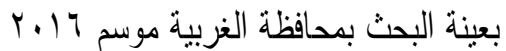

\begin{tabular}{|c|c|c|c|c|c|}
\hline المحسوبة & $\overline{\mathrm{R}^{2}}$ & المرونة & المعالةة المقلرة & الفئة الحيازية & e \\
\hline $113.69 * *$ & 0.91 & 1.327 & 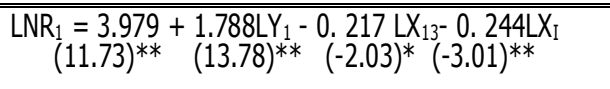 & الفئة الأولي & 1 \\
\hline $100.33^{* *}$ & 0.78 & 0.94 & $\begin{aligned} \operatorname{LNR}_{2}= & 4.995+1.68 \mathrm{LY} \mathrm{Y}_{2}+0.282 \mathrm{LX}_{13}-0.458 \mathrm{LX} \mathrm{I}_{\mathrm{I}} \\
& (33.76)^{* *}(17.13) * *(-5.61)^{*}(-8.85)^{* *}\end{aligned}$ & الفئة الثانانة & $r$ \\
\hline
\end{tabular}

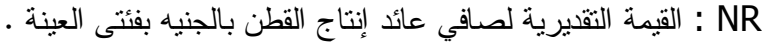

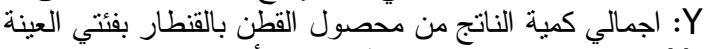

X

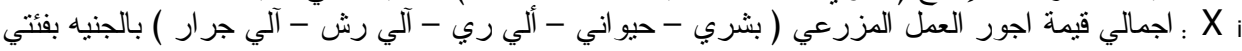

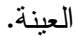


وقد تبين من الدالة أن أهم العو امل تأثثيرا علي صافي العائد الفدانى لمحصول القطن لهذه الفئة

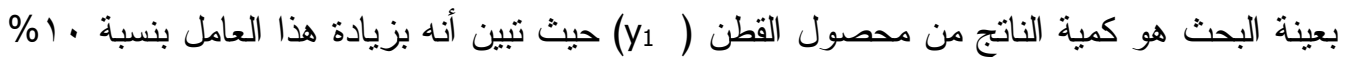

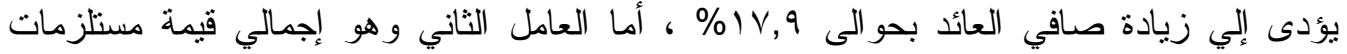

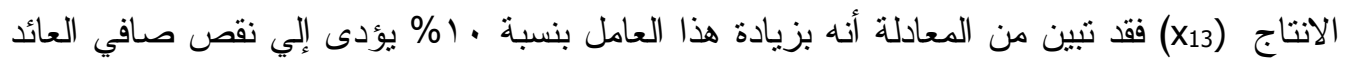

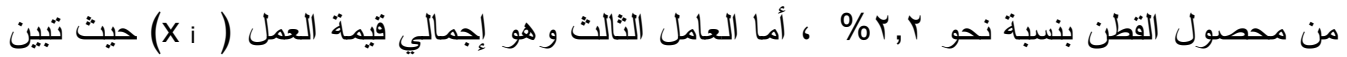

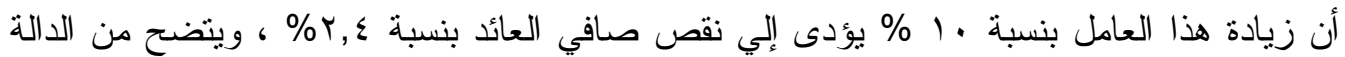

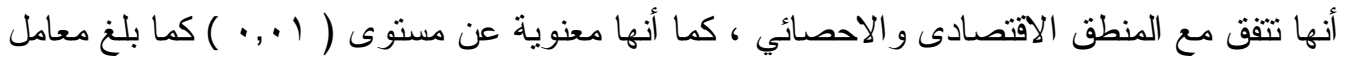
التحديد المعدل نحو ا9,, ، أى أن هذه العوامل مجتمعة تقسر نحو ا99\% من إجمالي العوامل المؤثرة على صافي العائد من محصول القطن بهذه الفئة . ب- الثقدير القياسي لالة صافي عائد انتاج القطن في الفئة الثانية :

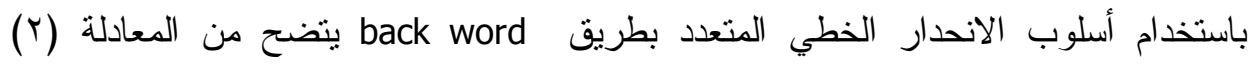
بالجدول (9) أن هناك علاقة دالية لو غاريتمية مزدوجة بين صافي العائد من محصول القطن بعينة

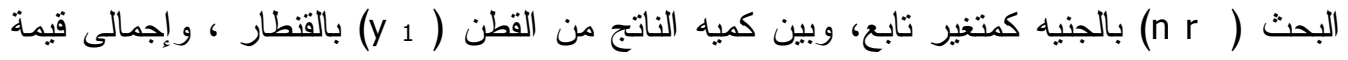

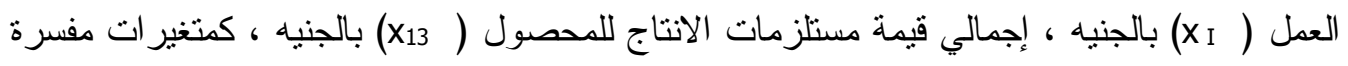

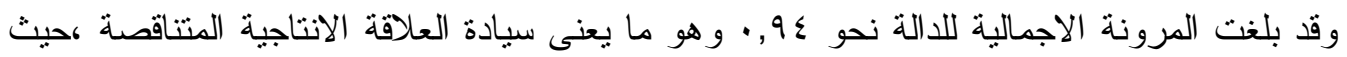

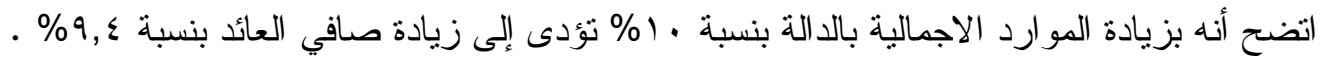
وقد تنين من الدالة أن أهم العوامل تأثثر ا على صافي العائد من محصول القطن لهذه الفئ الفئة

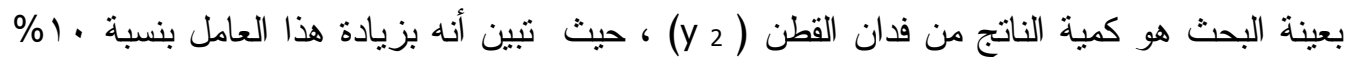

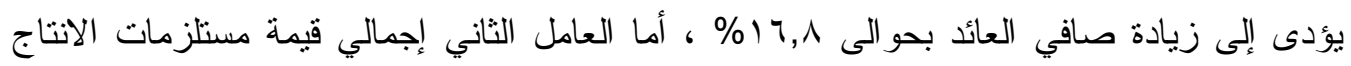

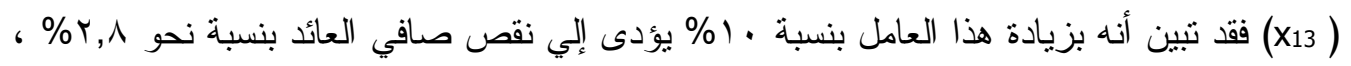

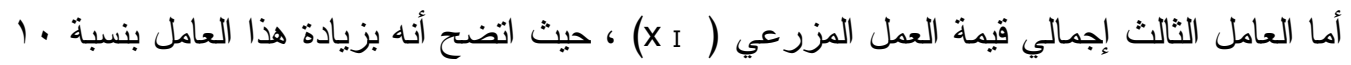

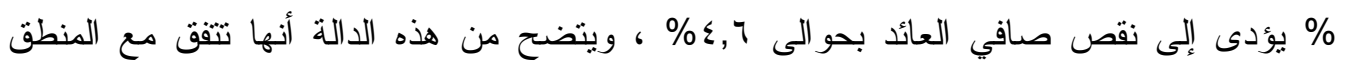

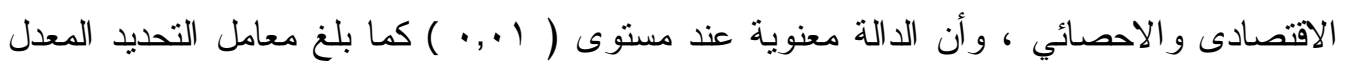

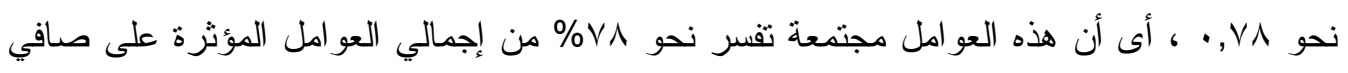
العائد من محصول القطن بهذه الفئة بفرض بقاء العو امل الأخري ثابتة.

خامسا : دالة استجابة العرض لمحصول القطن بمحافظة الغربية

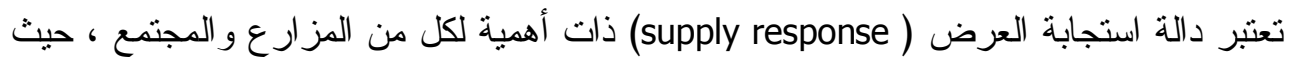
تساعد على اتخاذ المزارعين قرار زر اعة محصول ما من عدمه، ولتقدير استجابة العرض لمحصول القطن ، قد تم استخدام نموذج ( mark Nerlove) الديناميكى ، وقد تمت در اسة العلاقة بين المساحة

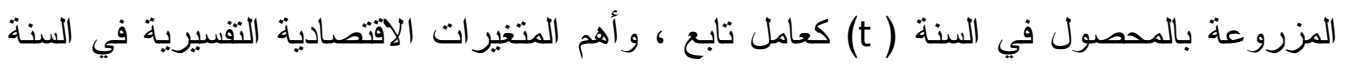

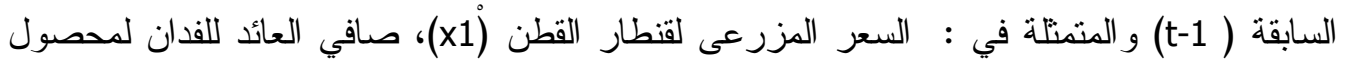

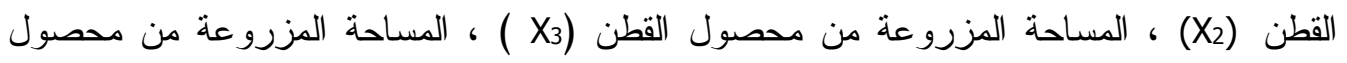

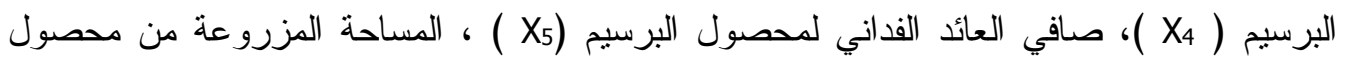


أذرة ( X6 )، صافي العائد الفداني لمحصول الأذرة (X7) ) ، وذلك باستخدام نموذج الانحدار المتعدد

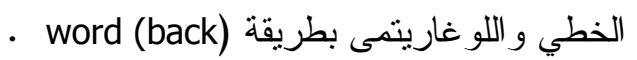
وبمقارنة الدو ال المقدرة و اختيار أفضلها بحيث تتمشي مع المنطق الاقتصادى و الاحصائي بعد

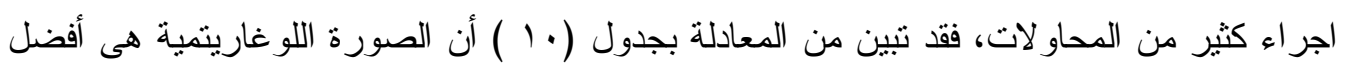
النماذج حيث تبين وجود علاقة طردية بين المساحة المزروعة بمحصول القطن في العام ( t) وبين صافي العائد للفدان من المحصول في العام السابق ، بينما نوجد علاقة عكسية بين المساحة المزروعة بمحصول القطن وصافي العائد الفدانى لمحصول البرسيم في العام السابق خلا فلى فترة البحث و أيضا علاقة عكسية بين المساحة المزروعة بالمحصول وصافي العائد الفدانى لمحصول

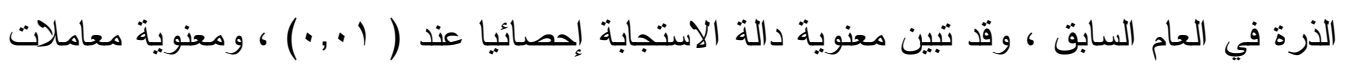

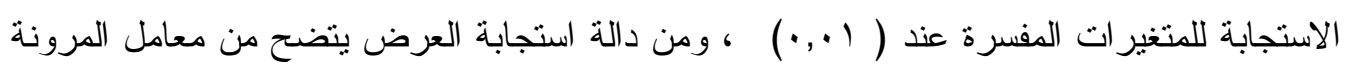

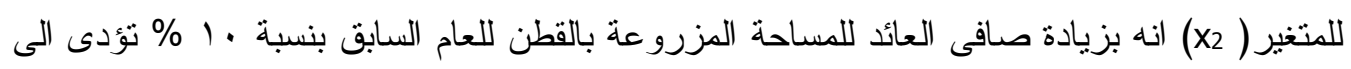

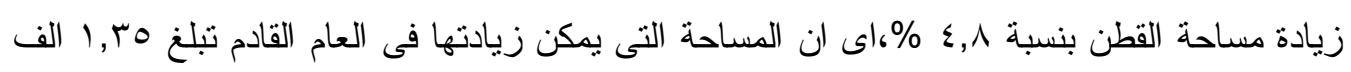

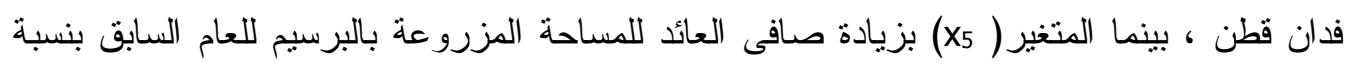

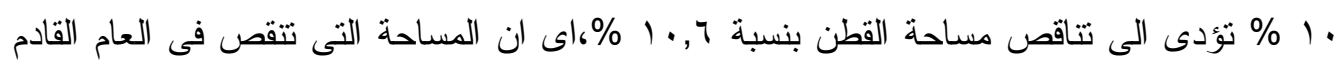

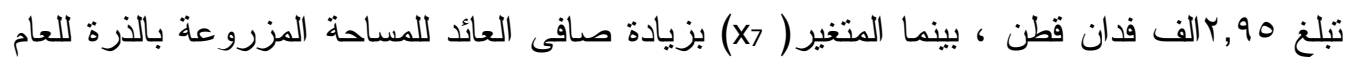

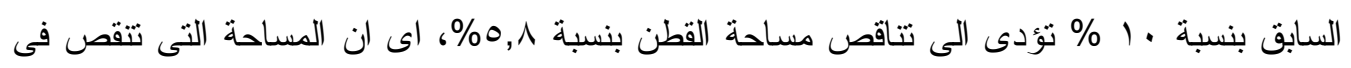

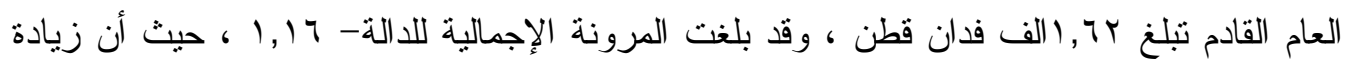

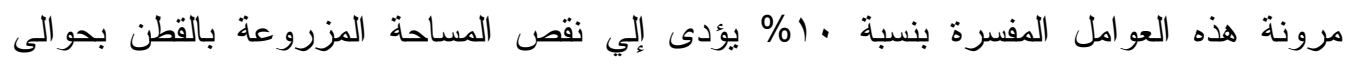

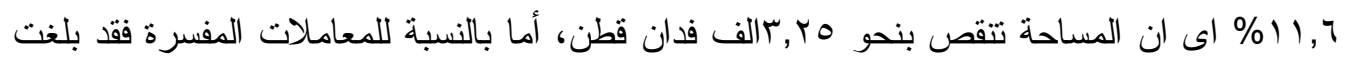

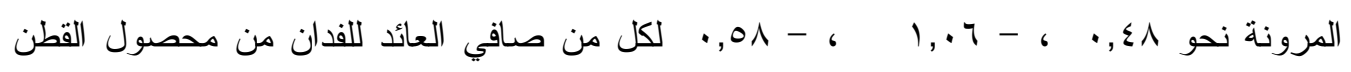
بفترة تأخير سنة ، وصافي عائد الفدان من البرسيم المستديم بفترة تأخير سنة ، وصافي عائد الفدان

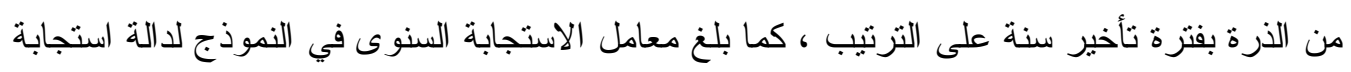

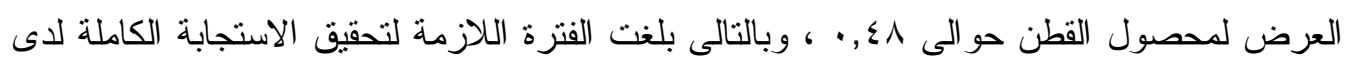

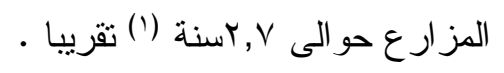

جدول رقم (• ( ) ): ثقدير استجابة العرض لمحصول القطن بمحافظة الغربية

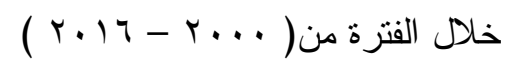

\begin{tabular}{|c|c|c|c|c|}
\hline $\begin{array}{c}\text { F } \\
\text { المسوبة }\end{array}$ & $\begin{array}{l}- \\
\mathrm{R}^{2}\end{array}$ & المرونة & النموذج & المعادلة \\
\hline $40.81^{* *}$ & 0.88 & -1.158 & $\begin{array}{c}L y_{i}=5.569+0.479 L X_{2}-1.059 L X_{5}-0.578 L X_{7} \\
(14.2)^{* *}(3.88)^{* *} \quad(-8.48)^{* *}(-4.07)^{* *}\end{array}$ & اللوغاريتمية \\
\hline
\end{tabular}

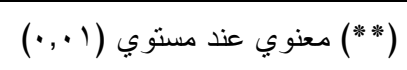

$$
\begin{array}{r}
\cdot r V_{-}=1, r V_{-} 1=(L Y-1)=\boldsymbol{\lambda}(1) \\
Y, V=\cdot \sigma V V / 1=1 / \lambda
\end{array}
$$




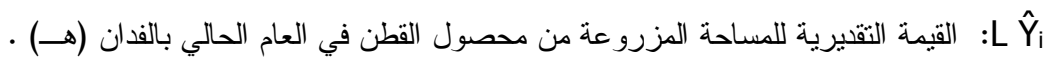

X2

X5

X7

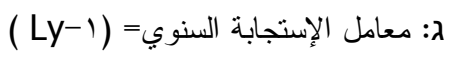

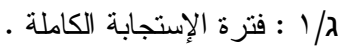

$$
\text { Log : L }
$$

المصدر : حسبت وجمعت من بيانات جدول (ץ) بالملحق.

$$
\text { الملاحق }
$$

ملحق (1) تطور المساحة والانتاجية و الانتاج لمحصول القطن في محافظة الغربية

\begin{tabular}{|c|c|c|c|}
\hline 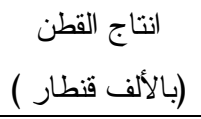 & 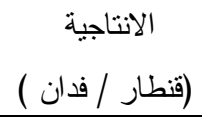 & 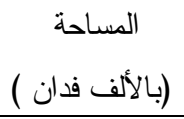 & السنو ات \\
\hline rV & $\vee, \wedge \uparrow$ & $r_{0,1 V}$ & $r \ldots$ \\
\hline$r \leqslant 1, \Lambda$ & 0,90 & ov,o. & $r \ldots l$ \\
\hline$\varepsilon \leqslant \Lambda, r$ & $\checkmark, \wedge r$ & OV,r $\mathrm{L}$ & $r \ldots r$ \\
\hline T, • וץ & $\Lambda, r \varepsilon$ & $r V, Y \leq$ & $r \ldots r$ \\
\hline ros, 0 & V,Or & $\leqslant V, 09$ & $r \ldots \varepsilon$ \\
\hline$M \quad V, T$ & ג, & $r \wedge, 1 \leq$ & r... \\
\hline$r V \varepsilon, r$ & $9, \Upsilon_{\wedge}$ & $r 9,00$ & $r \ldots r$ \\
\hline M19,7 & $\wedge, \vee q$ & ru, זo & $r \ldots v$ \\
\hline $1 \leq r, r$ & $\Lambda, r_{0}$ & $I V, Y \leq$ & $r \ldots \wedge$ \\
\hline $1 \leqslant r, r$ & $\Lambda, \varepsilon r$ & $17, \wedge 9$ & $r \ldots q$ \\
\hline 100,0 & $1,0$. & $11, Y 7$ & $r \cdot 1$. \\
\hline$r r_{q, 0}$ & $\wedge, 9$. & ro, $\vee q$ & $r .11$ \\
\hline $\mid r \varepsilon, V$ & $\wedge$ & $17, \wedge \leq$ & $r .1 r$ \\
\hline $1 \cdot 7, V$ & $Q, Y r$ & $11,0 \mathrm{~V}$ & $r .1 r$ \\
\hline $1 \leq r, \wedge$ & $\wedge, \Sigma \Gamma$ & $1 V, \cdot T$ & $r \cdot 1 \leq$ \\
\hline Vז, וד & $\neg, \cdot V$ & $1 ., 11$ & $r .10$ \\
\hline$\leqslant 0, V$. & $\wedge, 97$ & 0,1 . & $r .17$ \\
\hline$r Y \varepsilon, .0$ & $\wedge, 17$ & r^, l. & المتوسط \\
\hline
\end{tabular}

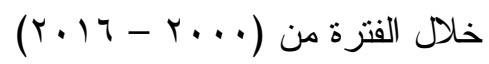

المصدر : جمعت وحببت من : مديرية الزر اعة بالغربية ، سجلات إدارة الإحصاء ، بيانات غير منشورة . 
ملحق (Y) الكفاءة الاقتصادية لعناصر انتاج محصول القطن لعينة البحث بمحافظة الغربية موسم 7 ـ ب

\begin{tabular}{|c|c|c|c|c|c|c|c|c|c|c|}
\hline الإقتصادية & بالجنية & بالناتيمة & للالعنصر & العنصر & النتاتج & الوالوسط & اللوالو الوسني & العنصر & إجاتج بالّالة قيمة & الفئة \\
\hline *** & $\{r, 19$ & $1 \cdot r, 0$ & 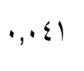 & צזr, & & $r \Lambda, 1 \Lambda$ & $1, \leqslant 0$ & $X_{1}$ & \multirow{2}{*}{$\begin{array}{l}=.00 \leqslant \varepsilon \\
L \hat{Y} \\
Y=r_{6} \leqslant 99\end{array}$} & \multirow{2}{*}{ الأولئة } \\
\hline ** & $0,4 q$ & YMY,O & r. & $\cdot, \varepsilon \cdot V$ & , YYA & $10, \mathrm{r} \mathrm{A}$ & $1,1 \wedge V$ & $X_{6}$ & & \\
\hline ** & $0, \varepsilon r$ & MYY,O & $\cdot, \cdot 19$ &,$r \wedge q$ & . & M & 1,009 & $X_{6}$ & \multirow{2}{*}{$\begin{array}{l}=\cdot(q r . \\
L \hat{Y} \\
Y=\Lambda, r) \Lambda\end{array}$} & \multirow{2}{*}{ الثناني } \\
\hline$* *$ & $r \leqslant, O r$ & YYY,O & $\cdot, .91$ & •, r10 & . & $19, V r$ & 1,190 & $X_{4}$ & & \\
\hline
\end{tabular}

المصدر : جمعت وحسبت من استمار ات الاستبيان الخاصة بالدر اسة .

ملحق (r) أهم العو امل الاقتصادية المحدد للرقعة المنزرعة من محصول القطن بمحافظة الغربية

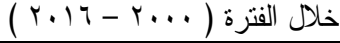

\begin{tabular}{|c|c|c|c|c|c|c|c|c|c|}
\hline الذافئد & ألمنزر ألمة & لـافئي & المنزر عة المسة & المنزرة المساحة & 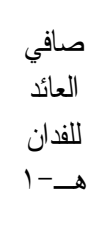 & هـ الفدان & المزرعى السعر & القطن & السنة \\
\hline 110 & $\wedge 9, r$ & $r \cdot \leqslant 1, \Lambda$ & $1 \pi \cdot, \varepsilon$ & $01, .1$ & TVO & $1 \Lambda \leqslant Y$ & $r \leqslant q$ & $r 0,1 V$ & $r \ldots$ \\
\hline$\varepsilon \wedge V$ & $\Lambda_{\cdot}, \varepsilon$ & YYq4,1 & $\| \wedge, r$ & $r_{0,1 V}$ & r. & T.OS & ro. & $O V, O$ & $r \ldots l$ \\
\hline org & $111, r$ & ro. I, & IYV,T & $O V, O$ & $\leqslant \leqslant 7$ & $r \cdot \Lambda V$ & $r \leqslant r$ & $O V, r \varepsilon$ & $r \ldots r$ \\
\hline $7 \leqslant 0$ & 94,7 & rTMO,r & $1 \Gamma_{0, \xi}$ & OV,r & Vo. & $r . T$. & $\varepsilon 1$. & $r V, Y \varepsilon$ & $r \ldots r$ \\
\hline ATI & $\wedge 9, \wedge$ & rAq & $1 \leqslant \cdot 0$ & $r V, Y \varepsilon$ & 177. & $r 110$ & Oro & $\sum V, 0 q$ & $r \ldots \varepsilon$ \\
\hline $19 \leq \leqslant$ & $V I, Y$ & $r 9 \wedge 1$ & $1 \leqslant 0, r$ & $\leqslant V, Y \leqslant$ & $r .10$ & KYVO & 710 & $\Gamma \wedge, 1 \leq$ & $r \ldots o$ \\
\hline $19 \leqslant 1$ & $9 \cdot, \varepsilon$ & $r \leqslant T r$ & 111,9 & $r \Lambda, 1 \leqslant$ & $19 \leqslant \wedge$ & YAYY & VIT & $r 9,00$ & Y.. T \\
\hline rIl. & $V \cdot, r$ & $r 4 \leqslant T$ & 117,1 & $r 9,00$ & rov. & rq१. & $\vee \wedge$. & ru, ro & $r \ldots V$ \\
\hline roor & 70,1 & Mro & $M V, \varepsilon$ & ru, ro & $11 \mathrm{~V}$. & $r \leqslant r_{0}$ & TVI & $I V, Y \varepsilon$ & $r \ldots \Lambda$ \\
\hline INT. & $77, Y$ & 07.1 & $1.0,0$ & $I V, Y \leq$ & 1.10 & हार. & $\Lambda .7$ & 17,19 & $r \ldots q$ \\
\hline 1.19 & $V \Psi, r$ & זדואד & $111, \wedge$ & $17, \wedge 9$ & IrA. & r990 & $7 V 9$ & $1 \Lambda, Y^{\prime}$ & $r .1$. \\
\hline $1 V \leqslant 9$ & $\Delta V, q$ & 77.1 & $11 r, r$ & $1 \Lambda, Y 4$ & $\varepsilon \mid r$. & $\$ 070$ & $\mid \pi \varepsilon$. & Yo, Vq & $r .11$ \\
\hline $1 \leqslant \varepsilon$. & $V_{\cdot}, \varepsilon Y$ & 974V & $M r, r$ & $r 0, v q$ & $r .00$ & 719. & 1.77 & $17, \wedge \varepsilon$ & $r . I r$ \\
\hline 190 & 74.5 & 1174. & $1 \cdot \varepsilon, r$ & $17, \wedge \varepsilon$ & FYYq & $0 \leqslant \wedge$. & 1179 & $11,0 \mathrm{~V}$ & $r .1 T$ \\
\hline $1 \leqslant r_{0}$ & 79,1 & $11 \leqslant 09$ & 91,0 & $11,0 \mathrm{~V}$ & rAr. & $07 Y 4$ & $1 \leqslant V \leqslant$ & $1 V, \cdot T$ & Y.I \\
\hline rqYI & $V I, r$ & $11 \leqslant v$. & $10, r$ & $1 V, \cdot Y$ & TVYO & 07rq & $I T \leqslant V$ & $1 \cdot, 11$ & $r .10$ \\
\hline TYTS & $\lambda_{\cdot}, r$ & $119 Y \leq$ & $9 \cdot, \varepsilon$ & $1 \cdot, 11$ & 190. & $07 \pi 1$ & $1 Y \leqslant 0$ & 0,1 . & 4.17 \\
\hline $1 \leqslant 9 \cdot, \wedge$ & $\Lambda \cdot, \cdot r$ & $094 \mathrm{~T}, \mathrm{r}$ & $110, \mathrm{~V}$ & $r \cdot, \wedge$ & $1 \vee \wedge 9,9$ & ruAv, \& & $\Lambda \backslash \leqslant, V$ & $r \wedge, 1$. & المتوسط \\
\hline
\end{tabular}

$\mathrm{Y}_{\mathrm{t}}=\mathrm{b}_{0}+\mathrm{b}_{1} \mathrm{X}_{\mathrm{t}-1}+\mathrm{b}_{2} \mathrm{Y}_{\mathrm{t}-1}$

$Y_{t}=b_{0} \lambda+b_{1} \lambda x_{T-1}+(1-\lambda) Y_{t-1}+\lambda u$

المصدر : جمعت وحسبت من : مديرية الزر اعة بالغربية ، إدارة الإحصاء ، بيانات غير منشورة . 


\section{التوصيات}

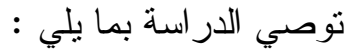

1- العمل على تحديد السعر المزرعى لمحصول القطن قبل موسم الزر اعة بمدة كافية تتجيعا

$$
\text { للز ارع نحو زر اعة المحصول. }
$$

r- العمل على تشجيع الزر اعة التعاقدية لمحصول القطن التى تساهم بدور ها فى حل مشاكل تسويق المحصول ،وضمان تسويقه و الحفاظ على حقوق المزارعين . r- يجب دعم مزارعى القطن من خلال نوفير وخفض اسعار مستلزمات الاتتاج (التقاوي و المبيدات والأسمدة الكيماوية) تشجيعا للزراع بزر اعة محصول القطن دون المحاصيل المنافسة .

ع- - ير اعي عند تحديد السعر المزرعى للمحصول ربط سعر الضمان بالعائد الصافي للمحاصيل الزر اعية المنافسة وبالاسعار العالمية .

ه- يوصي البحث بزراعة القطن في المزارع ذات السعات الكبيرة لخفض تكاليف الانتاج من

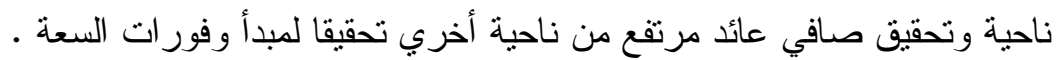

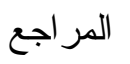

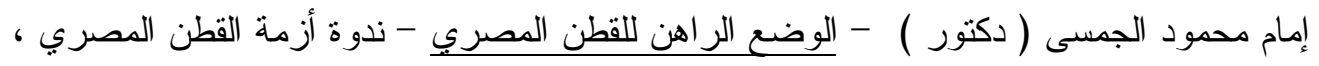

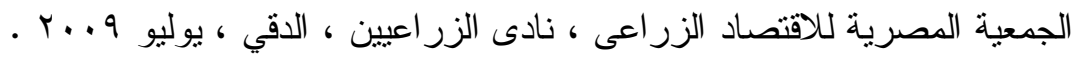

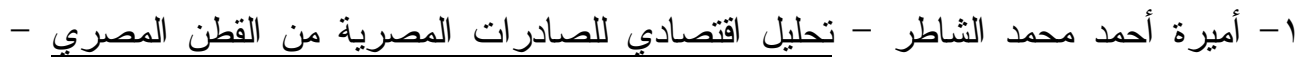

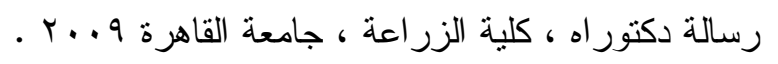

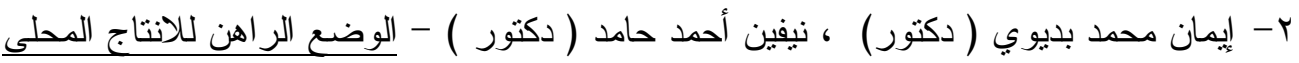

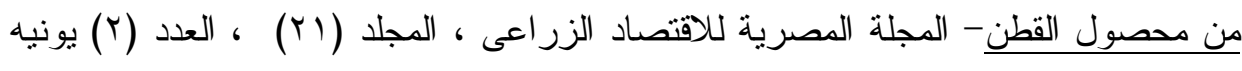

r- على عبد المحسن عبد الستار (دكتور ) - دراسة اقتصادية للسياسات السعرية الزراعية

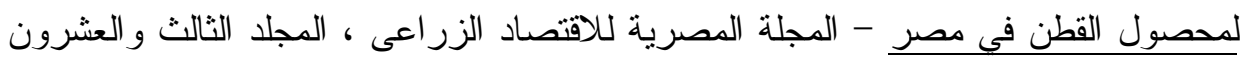

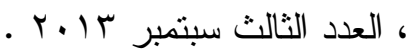
ع- عمر أحمد بدر (دكتور) ، اقتصاديات إنتاج القطن في محافظة الغربية ، المجلة المصرية

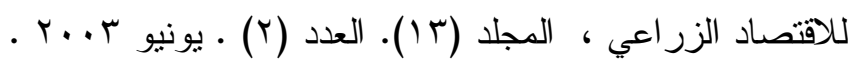

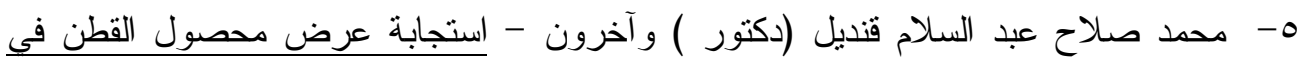
مصر - المجلة المصرية للاقتصاد الزراعى ، المجلد الثامن عثر ، العدد الثالث ، سبتمبر اعرئ r... צ- محمد عبد الرحمن نجم ( دكتور ) - الحالة الر اهنة لقطاع القطن المصري و الخطط المستقبلية

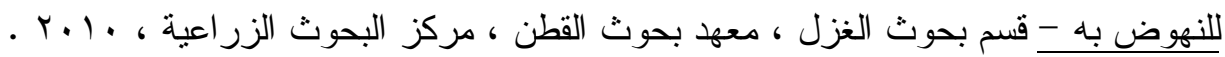




$$
\begin{aligned}
& \text { - Vحمد منير المعداوي - الاككانيات الاقتصادية لنطوير الموقف التتافسي للقطن المصري في }
\end{aligned}
$$

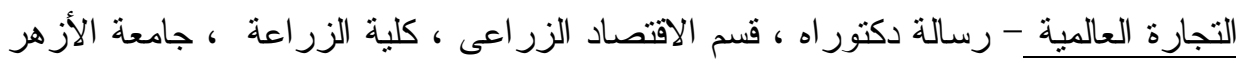

$$
\begin{aligned}
& \text { r.l. } \\
& \text { ^- ناصر محمد عبد العال سالمان - دراسة اقتصادية لإنتاج الأفطان المصرية - رسالة دكتور اه }
\end{aligned}
$$

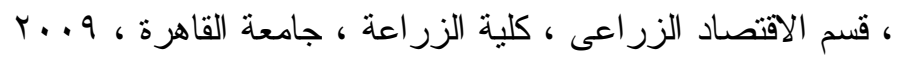

$$
\begin{aligned}
& \text { 9- هناء شداد عبد اللطيف - دراسة اقتصادية لاستجابة عرض بعض محاصيل الحبوب في }
\end{aligned}
$$

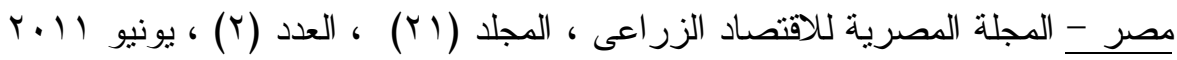

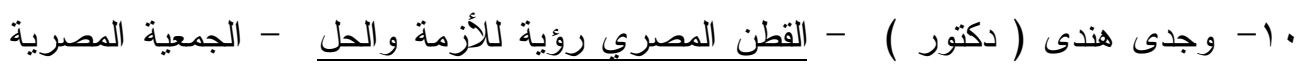

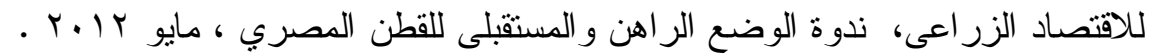

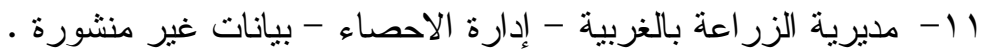

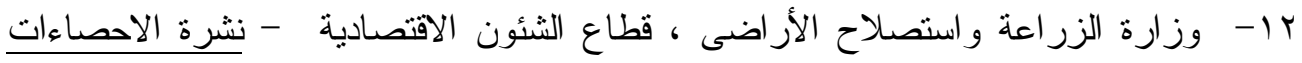

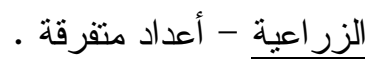

13- http : www.fao.org (2013) الموقع الالكتروني لمنظمة الأغذية و الزر اعة

14- Marc Nerlove . (1979) . the dynamics of supply : retrospect and prospect. discussion papers 394. northwestern university center for mathematical studies in economics and management science Mushtaq .k. and p . j dawson .2002

15- cotton world statistics. Bullation of International Cotton Advisory Committee. May. 1997 . 